\title{
Larval performance and skeletal deformities in farmed gilthead sea bream (Sparus aurata) fed with graded levels of Vitamin A enriched rotifers (Brachionus plicatilis)
}

\author{
Ignacio Fernández ${ }^{a,}{ }^{*}$, Francisco Hontoria ${ }^{b}$, Juan B. Ortiz-Delgado ${ }^{c}$, Yannis Kotzamanis ${ }^{d}$, \\ Alicia Estévez ${ }^{\mathrm{a}}$, Jose Luis Zambonino-Infante ${ }^{\mathrm{e}}$ and Enric Gisbert ${ }^{\mathrm{a}}$
}

\footnotetext{
a IRTA, Centre d'Aqüicultura, Crta. de Poblenou km 5.5, 43450 Sant Carles de la Ràpita, Tarragona, Spain

${ }^{b}$ Instituto de Acuicultura de Torre de la Sal (CSIC), 12595 Torre de la Sal, Castellón, Spain

c Andalusian Institute of Marine Sciences (CSIC), Campus Universitario Rio San Pedro, Apdo. Oficial, 11510, Puerto Real, Cádiz, Spain

${ }^{d}$ Hellenic Centre for Marine Research, Institute of Aquaculture, Agios Kosmas, Hellinikon 16777, Athens, Greece

e INRA-Ifremer, UMR Nutrition Aquaculture et Génomique, Centre de Brest, BP 70, 29280 Plouzané, France
}

*: Corresponding author : Ignacio Fernández, Tel.: +34 977745427; fax: +34 977443138, email address : Ignacio.Fernandez@irta.cat

\begin{abstract}
:
Several nutritional studies have found a direct effect of several vitamins in chondrogenic and osteogenic development during early life stages of marine fish species. In the present study, the effect of vitamin A (VA) in gilthead sea bream skeletogenesis was evaluated by means of four different dietary regimes (enriched rotifers) containing increasing levels of total VA $(75,109,188$ and 723 ng total VA $\left.\mathrm{mg}^{-1} \mathrm{DW}\right)$. Dietary treatments were offered to larvae during the rotifer-feeding phase (4-20 days after hatching), while later all groups were fed with Artemia nauplii and weaned onto the same inert diet. Different dietary doses of VA affected gilthead sea bream larval growth, survival, performance (maturation of the digestive system) and quality (incidence of skeletal deformities). Higher levels of dietary VA than those included in the commercial emulsion for rotifer enrichment led to different levels and typologies of skeletal deformities, indicating that gilthead sea bream larvae were very sensitive to small increases in dietary VA. The degree of ossification was affected by the level of VA in enriched rotifers: the higher amount of VA in the diet, the higher number of skeletal pieces ossified $(R=0.585, P=0.04)$. Dietary VA affected the normal process of bone formation and skeletogenesis, the skeletal structures mostly affected by high amounts of dietary VA were those from the cranial skeleton (splanchnocranium), vertebral centrums and caudal fin complex. The premaxilla, maxilla and dentary bones were the cranial structures affected by dietary VA levels, resulting in a large incidence of animals with compressed snout. Dietary VA also affected the normal development of the opercular complex, and a dose-response dependant effect was observed in relation to the incidence of specimens with incomplete operculum. Body shape was also affected by the level of dietary VA, increasing the incidence of specimens with lordosis, kyphosis and/or scoliosis with the dose of VA, being the prehaemal and caudal vertebrae the most affected regions of the vertebral column with this kind of abnormalities. The caudal fin complex was the most affected region of the skeleton affected by dietary treatments as seen by the high incidence of skeletal deformities in fish fed different doses of dietary VA. Deformities affected all skeletal elements composing the caudal fin, although the most affected ones were, in order of importance, the epurals, hypurals, parahypural, neural arch and uroneurals. Differences in sensitivity to dietary VA amongst caudal fin skeletal elements might be due to their differential ontogenetic development and differences in the exposure time to VA.
\end{abstract}

An excess of dietary VA also accelerated the intramembranous ossification process of vertebral centrums leading to one or two supranumerary vertebrae, and a high incidence of fused and compressed vertebral centrums. The sensibility of the developing skeletal structures to dietary VA levels should incline us to test lower doses of VA in live preys enrichments during early larval stages and higher doses afterwards.

Keywords: Gilthead sea bream; Sparus aurata; Larval quality; Vitamin A; Skeleton; Deformities 


\section{1. Introduction}

68 Gilthead sea bream is one of the most important marine fish species farmed in the

69 Mediterranean region with a total production of $71,355 \mathrm{t}(\mathrm{FAO}, 2005)$. In this area, a high

70 competence between aquaculture companies and a reduction of the gilthead seabream market

71 price due to overproduction during recent years, have forced aquaculture industry to reduce

72 their production costs and improving their larval rearing efficiency. Skeletal deformities and

73 their incidence are one of the most important factors affecting fish farmer's production costs,

74 determining the external morphology, growth and fish survival rate (Matsusato, 1986; Divanach

75 et al., 1997; Koumoundouros et al., 2002). In the aquaculture industry, losses due to

76 deformities occur at two levels. At hatcheries, reducing larval survival rate and growth

77 efficiency in malformed fish; and at on-growing farms, where malformed market size fish have

78 to be discarded or sold at lower values than market prices. The levels of losses at either point

79 are different, depending on the species and the husbandry practices followed. In whatever

80 circumstance, these losses are substantial, in terms of productivity and profitability, since

81 skeletal deformities might affect up to the $30 \%$ of the production. This fact represents one of

82 the bottlenecks in actual marine aquaculture. The yearly production of more than 500 million

83 has a survival of less than $15-20 \%$. High mortalities during the first stages of development,

84 which are typical for marine aquaculture, are responsible for a loss of several millions of euros

85 (Subasinghe, 1997). Thus, reducing the incidence of larval deformities would reduce the

86 economic cost of production, both in the hatcheries and in the out-growing production sectors,

87 and improve the quality of the products.

88 Most of skeletal deformities appear during the larval and juvenile stages, where many

89 biological processes take place for organogenesis, morphogenesis and metamorphosis in a

90 very short time. The development of skeletal disorders is linked to a poorly understood

91 relationship between nutrition, environment and genetic factors. The larval stage is a very

92 sensitive period where the harmonious larval development depends on the physiological,

93 environmental, genetic, xenobiotic and nutritional factors (see review in Lall and Lewis, 2007). 
94 Among them, larval nutrition at first feeding is one of the key parameters that affect

95 skeletogenesis during early development. In this sense, several studies have demonstrated

96 that nutrients are responsible for the appearance of skeletal deformities when their level and/or

97 form of supply in the diet are inappropriate or unbalanced (Cahu et al. 2003, Lall and Lewis,

98 2007). The solution of the problem is strongly related to the understanding of the species- and

99 stage-specific environmental preferences and nutritional requirements of the fish larvae, as well

100 as to the ontogeny of the skeletogenesis and anatomy of each deformity type.

101 The effects of nutrition on bone development and remodelling have been deeply studied

102 in terrestrial vertebrates, whereas this information in fish is fragmentary depending on the

103 nutrient considered (Cahu et al., 2003; Lall and Lewis, 2007). In this sense, recent advances in

104 the composition of starter diets for marine finfish larvae and enriching emulsions for live preys

105 have identified several nutrients, particularly minerals, vitamins and lipids that can be critical for

106 normal skeletogenesis. Vitamin A (VA), a morphogenetic nutrient, includes all compounds that

107 posses the same biological activity of retinol, playing a key role in morphogenesis, cellular

108 differentiation and proliferation processes. VA determines normal growth, body patterning,

109 nervous system development, and differentiation of pigment cells, limbs and skeleton along

110 vertebrate early development (Ross et al., 2000). The fish are not able to synthesize VA, thus

111 they have to take it from diet and any excess or deficiency of this nutrient in the diet resulted in

112 abnormal growth and development (Dedi et al., 1995; Tarui et al., 2006; Takeuchi et al., 1998;

113 Haga et al., 2002 a, b; Villeneuve et al., 2005). The impact of dietary VA on fish larvae

114 development will depend on both the dietary dose and the developmental status of the larvae

115 at first feeding. It is then necessary to fine-tune this particular relationship for each species.

116 The objective of the present study was to evaluate the effect on larval performance

117 (growth, survival and maturation of the digestive function) and quality (incidence and typology

118 of skeletal deformities) of graded levels of dietary VA on gilthead sea bream larval

119 development. 


\section{2. Materials and methods}

\section{2.1 Larval rearing and diets}

123 Gilthead sea bream larvae were obtained from a Spanish private hatchery and shipped to the

124 IRTA facilities. After their acclimation, larvae were distributed (initial density: 100 larvae $\mathrm{L}^{-1}$ ) in

12524 cylindrical tanks (100 L) connected to a recirculation unit (Carbó et al., 2002). Water

126 conditions were as follows: $18-19^{\circ} \mathrm{C}, 35 \mathrm{ppt}$ salinity, $\mathrm{pH}$ between $7,8-8,2,20 \%$ daily water

127 exchange and with gently aeration and oxygenation ( $\left.>4 \mathrm{mg} \mathrm{I}^{-1}\right)$ Photoperiod was 12L:12D, and

128 light intensity of 500 lux at water surface.

129 Larvae were fed from day 4 post hatch (dph) to $20 \mathrm{dph}$ enriched rotifers (Brachionus

130 plicatilis, lorica length: $178 \pm 30 \mu \mathrm{m}$ length), whose density was progressively increased from 5

131 to 10 rotifers $\mathrm{ml}^{-1}$. Artemia nauplii (EG, INVE, Belgium) were offered to larvae from 16 to 22

$132 \mathrm{dph}$, in increasing density from 0.5 to 2 nauplii $\mathrm{ml}^{-1}$, and 2 days enriched-metanauplii from 20 to

$13340 \mathrm{dph}\left(1\right.$ to 5 metanauplii $\mathrm{ml}^{-1}$ ). From $36 \mathrm{dph}$ to the end of the experiment ( $60 \mathrm{dph}$ ), larvae

134 were progressively weaned onto dry feed, first with Proton 1/2 and 1/4 (INVE, Belgium) and

135 then with Gemma Micro (size range: 75 to $500 \mu \mathrm{m}$; Skretting, Spain).

136 The effect of VA in gilthead sea bream skeletogenesis was evaluated by means of four

137 different dietary regimes containing graded levels of VA using enriched rotifers. As rotifers and

138 Artemia nauplii accumulate VA in different patterns (Giménez et al., 2007), it was not possible

139 to maintain the same levels of VA during all the life prey-feeding period. Thus, we decided to

140 focus our study during only the rotifer-feeding phase. The graded VA levels on live prey were

141 obtained adding retinol palmitate $\left(1,600,000 \mathrm{IU} \mathrm{g}^{-1}\right.$, Sigma-Aldrich, Spain) to a commercial

142 enriching emulsion, Easy Selco ${ }^{\mathrm{TM}}$ (ES, INVE, Belgium). Theoretically, experimental emulsions

143 contained $450,900,2,250$ and 4,500 ng retinol equivalents $\mathrm{mg}^{-1}$ of emulsion in wet weight

144 (Table 1). Dietary treatments were named as R450, R900, R2,250 and R4,500 according to the

145 theoretical level of retinol contained in the enriching emulsion (wet weight). For comparative 
purposes, the emulsion containing $450 \mu \mathrm{g}$ retinol equivalents $\mathrm{g}^{-1}(\mathrm{R} 450)$ was considered as the 147 control group (ES without retinol palmitate addition).

148 Live prey (rotifers and Artemia nauplii) were enriched according to Gimenez et al. (2007), 149 rotifers were enriched during two hours with $0.15 \mathrm{~g}$ of each experimental emulsion per litre, and

150 Artemia metanauplii for $18 \mathrm{~h}$ with $0.6 \mathrm{~g} \mathrm{ES} \mathrm{I}^{-1}$. After enrichment, rotifers and Artemia were 151 gently siphoned from enriching tanks, collected in a mesh, and washed in freshwater to reduce

152 the bacterial load and rests of the enrichment emulsions. Live preys were introduced into the

153 rearing tanks three times per day in order to assure an optimal live prey density in the water 154 column, and their appropriate nutritional value.

155 The effects of graded levels of VA on gilthead sea bream larval performance and quality 156 was evaluated by quintuplicate (three tanks were used for regular sampling and two for final 157 survival). Larvae were sampled at 18 and $60 \mathrm{dph}$, coinciding with the end of the rotifer-feeding 158 phase and the end of the weaning period, respectively. For sampling purposes, larvae were 159 sacrificed with an overdose of anaesthetic (Tricaine methanesulfonate, MS-222, Sigma).

\subsection{Biochemical analysis}

162 Retinoids on enriching emulsions and live prey were analyzed by HPLC using a modification of 163 the method proposed by Takeuchi et al. (1998). After sampling, live prey were washed with 164 distilled water to remove marine salts and bacterial load, and samples were frozen at $-80^{\circ} \mathrm{C}$ 165 until posterior analysis. Lipids were extracted with a chloroform:methanol mixture (C:M, 2:1) 166 according to the Folch method (Folch et al., 1957), and stored in C:M:BHT (2:1:0.01) at $20 \mathrm{mg}$

$167 \mathrm{I}^{-1}$ at $-20^{\circ} \mathrm{C}$ until their analysis. Then, samples were evaporated and redissolved on 168 methanol:acetone (1:1 v/v) prior to their HPLC analysis. The HPLC system (Thermo Separation 169 Products, San Jose, CA, USA) was equipped with a Lichrospher C-18 reverse phase column 170 (Merck, Darmstadt, Germany) and a UV-visible detector set at a wavelength of $325 \mathrm{~nm}$. The 171 mobile phase was a mixture $(85: 15 \mathrm{v} / \mathrm{v})$ of $98 \%$ methanol with $0.5 \%$ ammonium acetate, and 172 chloroform. The flow rate was $1.5 \mathrm{ml} \mathrm{min}^{-1}$ and the elution time was $18 \mathrm{~min}$. The concentration 
173 of each retinoid was calculated from the calibration curves constructed with the peak area

174 ratios of their external standards and an internal standard of retinol acetate added to the

175 samples. All the reference retinoids were purchased to Sigma-Aldrich (Spain).

176

$177 \quad 2.3$ Larval growth and survival rate

178 Sampled larvae $(n=15)$ from each tank were washed with distilled water to avoid marine salts

179 and used for body size and dry weight determination. Larval standard length (Ls) was

180 measured with digital camera connected to a binocular microscope Nikon SMZ 800, AnalySIS

181 (Soft Imaging Systems, $\mathrm{GmbH}$ ). Once larvae were measured in length, they were dried at $60^{\circ} \mathrm{C}$

182 until their weight was constant. Samples were weighted with an analytic microbalance Sartorius

183 BP211D. At the end of the experiment, the total length of 150 fishes from each rearing tank

184 was measured to evaluate the effects of VA on size dispersion. Survival rate was calculated as

185 the percentage of final surviving fish in relation to the initial number at the beginning of the trial.

187 2.4 Maturation of the digestive system

188 The activity of two intestinal brush border enzymes (alkaline phosphatase and aminopeptidase

$189 \mathrm{~N}$ ) and two pancreatic enzymes (trypsin and amylase) was used to assess the degree of

190 development and maturation of the digestive system of larvae fed graded levels of VA. Enzyme

191 activity was measured at 18 and $60 \mathrm{dph}$ ( $n=50$ and 10 larvae per tank, respectively).

192 Sampled fish were washed with distilled water to avoid marine salts and stored at $-80^{\circ} \mathrm{C}$

193 prior to enzyme activity analysis. The whole $18 \mathrm{dph}$ larvae were homogenized for enzymatic

194 assays, since they were too small to dissect, while older fish were dissected to separate

195 pancreatic and intestinal segments as described by Cahu and Zambonino-Infante (1994).

196 Samples were homogenized (Ultra-Turrax T25 basic, IKA ${ }^{\odot}$ - Werke) in five volumes (v/w) of

197 ice-cold Milli-Q water, centrifuged at 3,300 $\mathrm{g}$ for $3 \mathrm{~min}$ at $4^{\circ} \mathrm{C}$ and the supernatant removed for

198 enzyme quantification. For determination of intestinal enzymes, samples were homogenized in 
cold Mannitol $50 \mathrm{mM}$, Tris-HCl 2 mM buffer, pH 7.0. Intestinal brush border membranes were

200 purified according to the method developed for intestinal scrapping (Crane et al., 1979).

201 Trypsin (E.C. 3.4.21.4) activity was assayed according to Holm et al. (1988), at $25^{\circ} \mathrm{C}$

202 using BAPNA (N-a-benzoyl-DL-arginine $p$-nitroanilide) as substrate. Amylase (E.C. 3.2.1.1)

203 activity was measured according to Métais and Bieth (1968), using soluble starch (0.3\%)

204 dissolved in $\mathrm{Na}_{2} \mathrm{HPO}_{4}$ buffer $\mathrm{pH} 7.4$ as substrate.

$205 \quad$ Alkaline phosphatase (E.C. 3.1.3.1) was quantified at $37^{\circ} \mathrm{C}$ using 4-nitrophenyl

206 phosphate (PNPP) as substrate (Bessey et al., 1946). Aminopeptidase N (E.C.3.4.11.2) was

207 determined at $25^{\circ} \mathrm{C}$ according to Maroux et al. (1973), using sodium phosphate buffer $80 \mathrm{mM}$

$208(\mathrm{pH}=7.0)$ and L-leucine $p$-nitroanilide as substrate (in $0.1 \mathrm{mM}$ DMSO). Enzymatic activities

209 were expressed as the specific activity, milli-units per milligram of protein ( $\mathrm{mU} / \mathrm{mg}$ protein), and

210 soluble protein of crude enzyme extracts was quantified by means of the Bradford's method

211 (Bradford, 1976) using bovine serum albumin as standard. All the assays were conducted in

212 triplicate.

213

2142.5 Skeletal deformities analysis, observations and measurements

215 To identify and quantify the skeletal deformities on larvae from different dietary treatments, 50-

21660 larvae per each tank were sampled at the end of the experiment, and fixed in formaldehyde

217 solution (10\%) until their double staining. Then, animals were stained for bone and cartilage on

218 whole mounts using a modification of the method described by Klymkowsky and Hanken

219 (1991). In brief, specimens were rehydrated two times in distilled water during 5 minutes and

220 then placed in alcohol $95^{\circ}$. Specimens were stained with alcian blue solution with $80 \%$ alcohol

$22195^{\circ}$ and $20 \%$ glacial acetic acid during 24 hours, rehydrated through a graded series of alcohol

$222(95 \%-25 \%)$ and macerated using a 1\% aqueous solution of $\mathrm{KOH}$ with $3 \%$ hydrogen peroxide

223 (9:1 in volume) until skeletal elements were clearly visible. Then, specimens were placed

224 between 6 and 20 hours in an aqueous solution saturated in sodium borate containing 0.3-0.5

$225 \mathrm{~g}$ trypsin, and stained with alizarin red S (stock solution: 1\% alizarin red in 1\% $\mathrm{KOH}$ ) during 24 
hours. Staining time was variable and depended on the size of the specimen. Finally, fish were

227 washed with distilled water, followed by a series of baths in $1 \% \mathrm{KOH}$ to remove the excess of

228 dye in soft tissues, and placed through graded series of glycerine- $\mathrm{KOH}$ solutions.

229 After staining, fish were placed on their right side, in order to observe meristic

230 characters and skeletal abnormalities in the cranium, vertebral column and caudal fin complex.

231 Skeletal structures were identified and named according to Faustino and Power (1998, 1999,

232 2001). The study was focused on the mean number of vertebra and frequency of individuals

233 with abnormal number of vertebrae. Special emphasis was placed on the deformities occurring

234 in the cranial region (upper and lower jaws), vertebral column and caudal fin complex (hypurals

235 and parahypurals, epurals, uroneural, and specialized neural arch). In particular, we calculated

236 the frequency of individuals with lordosis, scoliosis or kyphosis, the total sum of deformities in

237 the vertebral column, and the incidence of vertebral compression and fusion.

238 In order to assess the degree of ossification of gilthead sea bream juveniles and

239 establish a potential relationship with the dietary regimen during the larval stages, the

240 percentage of juveniles in different stages of ossification was determined at the end of the

241 experiment. Those stages were defined according to the ossification of selected bony

242 structures that better describes the ossification process in this species (Faustino and Power,

243 1998). In brief, stage I corresponded to the early ossification of some vertebral centrums; at

244 stage II, all vertebral centrums were completely ossified; and at the stage III, dorsal fin rays

245 were completely ossified. At stage IV, caudal fin rays were ossified, and at stage $\mathrm{V}$, the

246 hypurals and parahypural started to ossify. The stage VI was characterized by the complete

247 ossificatifon of most of the skeletal structures with the exception of the uroneural 2 and the

248 haemal spines 2 and 3, which completed their ossification at older ages (larger sizes).

$250 \quad 2.6$ Statistical analysis

251 Results are given as means and standard deviations. Data expressed as percentage (survival, 252 incidence of skeletal deformities) were previously $\arcsin \left(x^{1 / 2}\right)$-transformed. Results were 
compared by means of One Way ANOVA (data normally distributed, Kolmogorov-Smirnov

254 test) and when significant differences were detected the Tukey multiple-comparison test was

255 used to detect differences among experimental groups (Zar, 1974). The test of Kolgomorov-

256 Smirnov was used to evaluate the distribution of fish size at the end of the study. Correlation

257 between different variables was evaluated with the Pearson Product Moment Correlation test.

258 In all statistical analyses, the level of significant difference was set at $P<0.05$. All the statistical

259 analyses were conducted using SigmaStat 3.0 (SPSS, Richmond, USA).

\section{Results}

\section{$264 \quad 3.1$ Retinoid content in experimental emulsions and live prey}

265 Total lipid and retinoid content in emulsions and rotifers enriched with graded levels of retinol

266 palmitate are presented in Tables 1 and 2, respectively. No statistically significant differences

267 were detected in the total lipid content of experimental emulsions and enriched rotifers with

268 different levels of VA (ANOVA, $P>0.05$ ). Total vitamin A content in emulsions and enriched

269 rotifers increased with increasing levels of retinyl palmitate incorporated into the emulsion

270 (ANOVA, $P<0.05$ ). Analysis of retinoid content of enriched rotifers showed that the real

271 incorporated level of total VA was $75,109,188$ and $723 \mathrm{ng} \mathrm{mg}^{-1} \mathrm{DW}$ for live prey enriched with

272 R450, R900, R2,250 and R4,500 experimental emulsions, respectively (Table 2). Retinyl

273 palmitate (VA ester) was the dominant form of retinoid detected in emulsions and enriched

274 rotifers, whereas retinol (VA alcohol) was also detected but at a minor concentration. Either

275 retinal (aldehyde form of vitamin A) was not detected in emulsions or rotifers enriched with

276 graded levels of vitamin A, whereas low levels of retinoic acid (0.8-1.1 $\left.\mathrm{ng} \mathrm{mg}^{-1} \mathrm{DW}\right)$ were only

277 detected in enriched rotifers, although they were not significantly different amongst rotifers

278 enriched with graded levels of VA (ANOVA, $P>0.05)$. 


\subsection{Larval growth and survival}

281 Table 3 contains the results of growth in length and DW of gilthead seabream larvae fed

282 different levels of VA. At $18 \mathrm{dph}$, no statistically significant differences were observed in DW in 283 larvae fed graded levels of VA during the rotifer-feeding phase, while fish fed rotifers enriched

284 with the control emulsion showed the best growth in length (ANOVA, $P<0.05$ ). At the end of 285 the trial, larvae fed R450 and R900 were larger in length and DW (ANOVA, $P<0.05$ ). Larvae 286 fed rotifers enriched with higher doses of total VA (R2,250 and R4,500) weighted 12 and 21\% 287 less than the other groups. Similarly, the length of those fish was 3 and $7 \%$ smaller.

288 The frequency distribution of final Ls classes in experimental groups fed rotifers 289 enriched with R450, R900 and R2,250 followed a normal distribution. The Kolmogorov290 Smirnov test, however, revealed statistically significant differences between the final 291 distribution of Ls of fish fed rotifers enriched with the highest dose of total VA $(R 4,500)$, 292 skewing the distribution towards sizes classes comprised between 15 and $17 \mathrm{~mm}(P<0.05$; 293 Fig. 1).

294 Dietary levels of VA significantly affected fish larval survival (Table 3; ANOVA, $P<$ 295 0.05). Final survival ranged from 2.9 to $9.1 \%$ depending on the experimental group. The 296 highest survival results were obtained in larvae fed R450 and R900, while higher dietary levels 297 of VA (R2,250 and $R 4,500)$ significantly reduce their viability.

\subsection{Maturation of the digestive system}

301 At the end of the rotifer-feeding period, the different VA levels in enriched rotifers significantly

302 affected the trypsin activity (ANOVA, $P<0.05$, Fig. 2a), while no significant differences were

303 detected in amylase secretion (ANOVA, $P>0.05$, Fig. 2b). At $18 \mathrm{dph}$, the specific trypsin in

304 larvae fed R450 was 2 times higher than in larvae from the other dietary treatments. At the end 305 of weaning (60 dph), no statistical significant differences in specific trypsin and amylase 
activities were detected among larvae from different experimental groups (ANOVA, $P>0.05$,

307 Fig. 2c, d).

308 The specific activity of intestinal brush border enzymes was also affected by the dietary 309 content of VA in enriched rotifers, although the trend in the specific activity of both enzymes

310 was different depending on sampling date. At the rotifer-feeding phase, the highest alkaline 311 phosphatase specific activity was measured in larvae fed the highest dose of VA in enriched

312 rotifers $(\mathrm{R} 4,500)$ (ANOVA, $P<0.05$; Fig. 3a), while specific activity of aminopeptidase $\mathrm{N}$ in the

313 above-mentioned group was the lowest amongst all four tested experimental groups (ANOVA,

$314 P<0.05$; Fig. 3b). At $60 \mathrm{dph}$, the alkaline phosphatase specific activity in fish fed R450 and

315 R900 was $80 \%$ higher than those fed higher levels of VA (ANOVA, $P<0.05$; Fig. 3c).

316 Aminopeptidase $\mathrm{N}$ specific activities followed the same trend than alkaline phosphatase. The

317 highest activities were recorded in fish fed R450 and R900, which were 4 times higher than

318 those in larvae fed R2,250; while intermediate values were detected in fish fed rotifers

319 containing the highest dose of VA (Fig. 3d).

\subsection{Skeletal deformities: typology and frequencies}

323 The typology and incidence of skeletal deformities in gilthead sea bream juveniles fed different 324 levels of VA during the rotifer-feeding phase are shown in Figures 4-11.

325 The degree of ossification was affected by the level of dietary VA in enriched rotifers

326 (Figure 4): the higher amount of VA in the diet, the higher number of skeletal pieces ossified ( $R$ $327=0.585, P=0.04)$. Fish fed the highest dose of VA showed the highest frequency of specimens

328 in most advanced stages of ossification (69.6\% in stages $\mathrm{V}$ and $\mathrm{VI}$ ) in contrast with those fed

329 the control diet, which only showed the $39.2 \%$ of specimens. However, the above-mentioned

330 data were not significantly different due to large variability in the ossification process between

331 replicates from the same dietary treatment. 
The presence of cranial skeletal deformities in the jaw apparatus was strongly

333 correlated to the level of retinoids in enriched rotifers $(R=0.789, P=0.002)$ (Fig. 6a). The

334 premaxilla, maxilla and dentary bones were the cranial structures more affected by different

335 levels of dietary VA, resulting in large number of specimens with compressed snout

336 (pugheadness, underdevelopment of the maxilla and premaxilla, Fig 5). The incidence of jaw

337 deformities in larvae fed the highest doses of VA (R2,250 and R4,500) were significantly higher

338 than those observed in juveniles fed lower levels of VA (ANOVA, $P<0.05$; Fig. 6a). No

339 statistical significant differences were detected regarding the incidence of jaw deformities

340 between larvae fed R450 and R900 (ANOVA, $P>0.05$ ). However, fish fed R900 showed a

341 higher incidence of deformities in both jaws in the same specimen, while this type of

342 deformation was not observed in the control group (Fig, 6b).

343 The incidence of opercular deformities was significantly correlated to the dose of VA in

344 enriched rotifers $(R=0.843, P=0,001$; Fig. 6 c). While the control group had $16.5 \pm 1.64 \%$ of

345 the individuals with an incomplete operculum, the incidence of this kind of deformity reached

$34639.2 \pm 3.05 \%$, in those fish fed R4,500 (ANOVA; $P<0.05$ ). Significant statistical differences

347 were also detected in the incidence of deformed operculum depending on the fish side

348 considered, indicating that the expression of this type of deformity was side-dependent. In all

349 experimental groups, the frequency of abnormal operculum was higher in the left than in the

350 right side, independently of the level of dietary VA (t-test, $P<0.05$; Fig. 6d). However, no

351 statistically significant differences were detected in the frequency of individuals with bilateral or

352 right-sided opercular complex deformities (ANOVA, $P>0.05$ ).

353 The number of vertebrae most frequently observed in gilthead sea bream is twenty-four.

354 At the end of the experimental period, statistically significant differences in the mean number of

355 vertebrae were detected between larvae fed R900 and the rest of dietary treatments (ANOVA,

$356 P<0.001 ;$ Fig. 7). Fish from this experimental group showed a higher frequency of specimens

357 with twenty-five (69.1\%) and twenty-six vertebrae (24.2\%). Those supranumerary vertebrae 
were observed in the caudal region, between the urostyle and vertebra number 23 , and were significantly correlated to vertebral fusion and compression disorders $(R=0.959, P<0.0001)$. The incidence of specimens with lordotic, kyphotic or scoliotic bends in their vertebral column tended to increase with increasing levels of total VA in enriched rotifers, although this trend was not significant $(R=0.564, P=0.056)$ due to the large variability of replicates.

Similarly, no significant differences could be detected between experimental groups (ANOVA, $P>0.05$; Fig. 8a, 9).

The frequencies of deformities in vertebral centrums were significantly affected by the level of VA in the diet (Fig. 8b). In all treatments, the compression of vertebral centrums was more frequent than their fusion with the adjacent ones (Fig, 8c, d). In particular, larvae fed R900 showed the highest incidence of compressed (80\%) and fused (40\%) vertebral bodies than the rest of the experimental groups (ANOVA, $P<0.05$ ). The incidence of both types of deformities in vertebral centrums was 65 and 33\% more frequent in the above-mentioned group than in larvae fed rotifers enriched with the control emulsion. Regarding the haemal and neural spines of vertebrae, in the haemal region of the vertebral column, haemal spines were significantly affected by the level of VA in the diet, increasing the incidence of twisted haemal spines with the dose of dietary VA (ANOVA, $P<0.05$ ). In contrast, no differences were detected in the incidence of deformities in the neural spine (ANOVA, $P>0.05$ ), although high variability between replicates and dietary groups was detected.

The incidence of skeletal deformities along the vertebral column in gilthead sea bream juveniles is shown in Figure 10. Independently of the level of VA in the diet, the caudal region was the area most affected by compression and fusion of the vertebral centrums; although the group fed R900 showed the highest percentage of compressed and fused vertebrae in this region; mostly affecting the urostyle (30\%) and vertebra number $23(90 \%)$. Vertebrae from the cephalic and prehaemal regions were also affected by the level of VA in the diet, thus juveniles fed rotifers containing high levels of VA during the rotifer-feeding phase showed a higher incidence of skeletal deformities in these regions ( $>10 \%$; ANOVA, $P<0.05)$. 

complex is presented in Figure 11 . Only the $29 \%$ of gilthead sea bream juveniles from the control group had at least one skeletal anomaly per fish in the caudal fin complex, while more than $90 \%$ of specimens fed higher levels of dietary VA had one or more types of deformities per specimen (Fig. 11a). The skeletal elements in the caudal fin complex most affected were the specialized neural arch, epurals, hypurals and parahypurals, and the uroneural. In most cases, deformities consisted in twisted or undeveloped skeletal elements and their fusion with adjacent ones. In particular, dietary levels of VA significantly affected the frequency of specimens with deformed specialized neural arch (ANOVA, $P<0.05$; Fig. 11b). Juveniles fed R900 showed the highest frequency (50\%) of specimens with this bonny element deformed in comparison to the other dietary treatments containing higher levels of VA, while none of the fish from the control group was detected with this type of skeletal deformity. The frequency of individuals with deformed epurals, hypurals and parahypurals was significantly higher in those treatments fed higher doses VA than in the control group (ANOVA, $P<0.05$; Fig. 11c, d). The increase in VA in the diet increased up to four and eight times the incidence of juveniles with deformed epurals, hypurals, and parahypurals, respectively. The incidence of deformities in the uroneural was lower than in the other caudal fin complex bonny pieces, affecting less than $5 \%$ of fish (Fig. 11e), although no statistically significant differences were detected in the frequency of specimens with deformed uroneural between different treatments due to the large variability observed amongst replicates and experimental groups (ANOVA, $P>0.05$ ).

Other minor skeletal deformities were also detected in gilthead sea bream juveniles, such as supranumerary predorsal fin rays $(<30 \%)$, and dorsal and ventral fin ray fusion $(<13 \%)$, although no statistical significant differences between experimental groups were detected in the frequency of specimens with such skeletal anomalies due to the large variability observed between dietary treatments and replicates. Due to their minor effect on the external appearance and fish quality, data on these deformities was deliberately not included. 


\section{Discussion}

413

414 Generally, marine fish larvae hatch much earlier in their development than other vertebrates,

415 suggesting that the spatiotemporal sequences of the skeletal development in teleosts are quite

416 different from those of higher vertebrates (Haga et al., 2002a). In gilthead sea bream larvae,

417 these developmental processes still continue after hatching, and this particularity facilitates

418 studies of the effects of nutrition on morphogenesis. In particular, several authors have

419 described the morphogenesis and osteogenesis processes in gilthead sea bream (Faustino

420 and Power, 1998, 1999, 2001; Koumoundouros et al., 1997a, b; 2002), while others have

421 focused their objectives in describing and quantifying the typology and incidence of skeletal

422 deformities in this species under different rearing conditions (Koumoundouros et al., 1997b,

423 2002; Chatain, 1994a; Andrades et al., 1996; Boglione et al., 2001). However, none of these

424 studies have evaluated the effect of the diet on skeletogenesis and appearance of skeletal

425 deformities during early ontogeny. In this sense, it has been recently demonstrated that the

426 morphogenesis of marine fish larvae could be perturbed by inappropriate dietary levels of

427 different nutrients (Takeuchi et al., 1998; Haga et al., 2002a, b; Villeneuve et al., 2005a, b;

428 Hernandez et al., 2006; Tarui et al., 2006). Thus, in the present study, we aimed to evaluate

429 the effects of different dietary levels of VA on the incidence of skeletal deformities and larval

430 performance in gilthead sea bream fed rotifers enriched with graded levels of this

431 morphogenetic nutrient.

432 The feeding protocol used in the present study makes difficult to perform accurate

433 nutritional studies, because of the variability of the nutrient content in live prey (Giménez et al.,

434 2007). However, the use of a balanced compound diet for this kind of study, as it has been

435 previously used in European sea bass (Villeneuve et al., 2005a, 2006), was discarded, since a

436 compound microdiet is not completely developed for first feeding gilthead sea bream. Lipid

437 content in rotifers after enrichment with graded levels of total VA was similar in all treatments.

438 This result indicates that the differences observed in total VA content in the live prey were only 
due to the levels of retinyl palmitate and retinol incorporated into the experimental emulsions

440 and cannot be related to the emulsion preparation and/or the enrichment conditions. Under the

441 present experimental conditions, total VA levels in rotifers increased proportionally to the

442 content of retinyl palmitate in the enriching emulsion. In agreement with Takeuchi et al. (1998)

443 and Giménez et al. (2007), the increase in retinol and retinoic acid, this last form of retinoid not

444 present in the enriching emulsion, indicated that rotifers were able to absorb, digest and

445 metabolize the retinyl palmitate contained in the enriching emulsion. Although retinoic acid is

446 the most active form of VA (Ross et al., 2000), the similar concentration of this retinoid in all

447 batches of enriched rotifers with experimental emulsions suggested that the observed effects of

448 VA on gilthead sea bream larval development were not due to its content in rotifers, rather than

449 the accumulation and transformation of different forms of VA in larvae.

450 At the end of the present experiment, , the different levels of dietary VA used during the

451 rotifer-feeding phase (4-18 dph) significantly affected gilthead sea bream larval growth and

452 survival, indicating that early larval nutrition exerted a strong effect on the further larval

453 performance. Larvae that showed the highest growth in length and dry weight, and survival

454 were those fed rotifers enriched with R450 and R900 emulsions, while higher dietary doses of

455 VA dramatically reduced larval performance. Similar results have been reported in other fish

456 species, such as Japanese flounder (Dedi et al. 1995; Takeuchi et al., 1995, 1998; Haga et al.

457 2003), European sea bass (Villeneuve et al., 2005a), red sea bream (Hernández et al., 2006)

458 and Atlantic salmon (Ørnsrud et al., 2002) where high dietary doses of VA led to a lower growth

459 and survival. However, the results from the above-mentioned studies are not directly

460 comparable due to different experimental dietary levels of VA, feeding protocols and diets (live

461 prey and inert diets). Nevertheless, survival and growth results observed in gilthead sea bream

462 larvae fed the control diet were similar to those obtained in commercial hatcheries (Tandler et

463 al., 1995; Başaran et al., 2004), ensuring that valid physiological and nutritional observations

464 could be drawn from this study. 

assimilating the ingested diet, incorporating the needed amount of nutrient required for normal

467 growth and harmonious development. Pancreatic and brush border intestinal enzyme activities have been widely used in nutritional studies as markers of larval fish development (ZamboninoInfante and Cahu, 2001). In this study, low trypsin specific activity at $18 \mathrm{dph}$ in gilthead sea bream larvae fed high levels of VA, might be indicative of a delay in the maturational process of

471 the exocrine pancreas, as Villeneuve et al. (2005a) already reported in European sea bass fed 472 inert diets containing different levels of dietary VA. However, dietary effects of VA

473 administrated during the rotifer feeding phase (4-18 dph) were not evident after larval weaning 474 at $60 \mathrm{dph}$, which might indicate that larvae fed high levels of VA were able to recover the normal digestive status regarding the pancreatic enzymes, once the excess of VA was eliminated from their diet (Artemia feeding and inert diet phases). In contrast to the results 477 reported by Villeneuve et al. (2006) with European sea bass fed high levels of VA, the specific activity of amylase in gilthead sea bream was not affected by the dietary levels of VA, although numeric values tended to decrease with dietary doses of VA, but they were not significant due to large variability between replicates and experimental treatments.

481 The specific activity of brush border intestinal enzymes was also affected by the dietary 482 dose of VA. Alkaline phosphatase is considered to serve as a marker for the maturation of the 483 brush border of enterocytes: the greater its activity, the better the level of intestinal maturation 484 (Zambonino-Infante and Cahu, 2001). However, high recorded activities of this brush border enzyme at $18 \mathrm{dph}$ in fish fed the highest dose of VA (R4500) in comparison to the rest of 486 dietary treatments might be attributed to an increase in cell proliferation (hyperplasia) induced 487 by dietary VA (Reifen et al., 1998; Uni et al., 2000), rather than a more advanced stage of 488 maturation of the intestinal mucosa, as aminopeptidase $\mathrm{N}$ specific activities indicated (three 489 times lower than in the other groups). At the end of the study, the low brush border enzyme 490 activity (alkaline phosphatase and aminopeptidase N) found in larvae from R2250 and R4500 491 groups, indicated dietary VA interfered with the normal development of the intestinal mucosa 
and consequently, this might have impaired normal larval growth and further development. It

493 has been reported in different vertebrate species that VA influences enterocyte proliferation

494 and maturation, and decreases brush border enzyme-specific activity (Reifen et al., 1998; Uni

495 et al., 2000; Villeneuve et al., 2005a).

496 Dietary VA also affected the normal process of bone formation and skeletogenesis in

497 gilthead sea bream. The skeletal structures most affected by high levels of dietary VA were

498 those from the cranial skeleton (splanchnocranium), vertebral centrums and caudal fin

499 complex. Many authors have reported that the operculum complex, premaxilla, maxilla and

500 dentary bones were the cranial structures mostly affected by skeletal deformities (Barahona-

501 Fernandes, 1982; Chatain, 1994b; Andrades et al., 1996; Francescon et al., 1988; Boglione et

502 al., 2001; Faustino and Power, 2001; Villeneuve et al., 2005). In this study, the premaxilla,

503 maxilla and dentary bones were the cranial structures affected by dietary VA levels, resulting in

504 a large incidence of animals with compressed snout. This kind of deformity is quite common in

505 gilhead sea bream intensive larval rearing conditions (Andrades et al., 1996; Loy et al., 1999;

506 Boglione et al., 2001) and it has been also reported in other finfish species (Barahona-

507 Fernandes, 1982; Haga et al., 2003; Villeneuve et al., 2005a, 2006). The high incidence of this

508 kind of deformity under current experimental conditions might be linked to the ontogeny of the

509 splanchnocranium formation in gilthead sea bream, since the maxillar, premaxillar and dentary

510 are some of the first skeletal structures to appear and ossify due to their important functional

511 roles (Faustino and Power, 2001), although the frequency of the detection might be influenced

512 by the fatal nature of these kinds of deformities (Barahona-Fernandes, 1982).

513 Under intensive rearing conditions, opercular abnormalities in gilthead sea bream can

514 affect up to $80 \%$ of the population, seriously compromising both fish morphology and biological

515 performance (Koumoundouros et al., 1997b). Considering that defects in the opercular

516 complex are frequent and have been reported in many different fish species (Barahona-

517 Fernandes, 1982; Beraldo et al., 2003; Fraser and Nys, 2005), this structure seems to be

518 fundamentally fragile and easily alterable during early development stages (Beraldo et al., 
519 2003). In the present study, opercular abnormalities in gilthead sea bream fed the control diet

520 were $15.0 \%$ and close to values reported by Galeotti et al. (2000). However, the level of dietary

521 VA affected the incidence of abnormal opercula, since the incidence of reduced opercula

522 increased with the levels of VA in enriched rotifers. Earlier studies on opercular deformities in

523 gilthead sea bream concluded that unilateral deformation was side-independent and hence it

524 was the result of a fluctuating asymmetry model (Koumoundouros et al., 1997b; Galeotti et al.,

525 2000; Beraldo et al., 2003). Surprisingly, under the present experimental conditions a high

526 frequency of reduced opercula was detected in the left side of the head. These results are in

527 agreement with those reported by Verhaegen et al. (2007) and suggested a directional

528 asymmetry model. Fluctuating asymmetry is believed to be a consequence of environmental

529 factors that have an effect on developmental instability during the early life stages (Barahona-

530 Fernandes, 1982; Koumoundouros et al., 1997b), while directional asymmetry is believed to be

531 an inherited factor. As Verhaegen et al. (2007) reported, the existing literature on the genetic

532 influence on the asymmetric development of opercular deformities is contradictory depending

533 on the species and study. Although a basic assumption of asymmetry research is that left and

534 right side experience identical environmental factors, this may not be the case under the

535 present rearing conditions where the hydrodynamics of the experimental tanks with a central

536 outlet might have caused a different opercular development on both sides of the body.

537 However, the aetiology of this type of skeletal deformity remains unclear and further studies

538 have to be conducted to elucidate if the cause is due to environment, to genetics or both.

539 Under the present experimental conditions, the levels of dietary VA affected the normal

540 skeletogenesis process of the vertebral column and the number of vertebrae. Other authors

541 have previously reported that the number of vertebrae in fish can be influenced by factors other

542 than nutrition, such as triploidy in trout (Kacem et al., 2004), or temperature in halibut (Lewis et

543 al., 2004). In gilthead sea bream, the mean number of vertebrae is twenty-four, although there

544 is some discrepancy in the literature about the frequency of individuals with one vertebra more

545 or less. In this sense, Boglione et al. (2001) found $75 \%$ of fish with twenty-three and twenty-five 
546 vertebrae, while the prevalence of fish with twenty-five vertebrae was only $5 \%$ according to

547 Faustino and Power (2001). Under the present experimental conditions, larvae fed the control

548 diet showed most part of fish with twenty-four vertebrae (75\%) and a low incidence of vertebral

549 deformities. Differences between these data might be due to other factors than nutritional

550 conditions, and could be related to different rearing conditions (e.g. extensive and intensive

551 rearing systems) and origin of larvae (e.g. egg quality and/or broodstock diet). However, the

552 level of dietary VA had a marked effect on the normal process of morphogenesis of the

553 vertebral column, since higher levels of VA than those from the control diet resulted in a higher

554 incidence of individuals with supranumerary vertebrae and a higher incidence of vertebral

555 deformities (compression and/or fusion of vertebral centrums). The morphogenetic effects of

556 VA on the normal development of the vertebral column have also been reported in Japanese

557 flounder (Haga et al., 2002a), European sea bass (Villeneuve et al., 2006) and red sea bream

558 Hernández et al. (2006). High levels of dietary VA in gilthead sea bream were responsible for a

559 higher incidence of specimens with a supranumerary vertebra in the caudal region of the

560 vertebral column, while in European sea bass larvae resulted in a loss of one vertebra. As

561 vertebrae from the caudal region are the last to ossify in gilthead sea bream (Faustino and

562 Power, 1998), an excess of dietary VA might have accelerated the normal differentiation

563 pattern of vertebral centrums and their osteogenesis, resulting in one or two supranumerary

564 vertebrae. Our hypothesis is supported by recent results (Mazurais et al., 2008) showing that

565 the dietary level of vitamins positively influence osteogenesis differentiation. These differences

566 in the effect of high levels of dietary VA in the number of vertebral centrums between both

567 species might be due to differences in the timing of notochord segmentation and vertebral

568 centrums formation, although further studies considering the expression pattern of genes

569 involved in larval morphogenesis and skeletogenesis are needed for comparing results from

570 both studies.

571 Body shape was also affected by the level of dietary VA, increasing the incidence of 572 specimens with lordosis, kyphosis and/or scoliosis with the dose of VA in the diet, being the 
573 prehaemal and caudal vertebrae the most affected regions of the vertebral column with this

574 kind of abnormalities. These results were similar to those reported in European sea bass

575 larvae, where the authors found a statistically significant linear correlation between the dietary

576 level of VA and the frequency of animals with deformities in their vertebral column (Villenueve

577 et al., 2005a). These kinds of deformities affecting the normal development of the vertebral

578 column have been described to affect larval performance and survival (Faustino and Power,

5792001 ; Koumoundouros et al., 2002); since they have been reported in specimens presenting a

580 smaller body size in comparison to non-affected fish (Koumoundouros et al., 2002). This kind

581 of skeletal deformities can also be induced by unfavourable rearing conditions, such as tank

582 hydrodynamics (Divanach et al., 1997), water temperature (Sfakianakis et al., 2006) or non-

583 inflation of the swimbladder (Chatain, 1994a). However, the absence of lordotic or kyphotic fish

584 from the control group indicated that the experimental rearing conditions were optimal for the

585 proper development of the skeleton, and consequently, skeletal abnormalities might be

586 attributed to the effect of dietary VA. Our data indicate that these anomalies in body shape

587 resulted from deformities (compression and fusion) of one or two vertebral centrums, as it was

588 previously reported in Japanese flounder (Takashima, 1978; Dedi et al., 1995) and red sea

589 bream (Hernandez et al., 2006). Deformities in vertebral centrums in the haemal and caudal

590 region of the vertebral column have been found to be significantly correlated with the number of

591 vertebrae. The appearance of supernumerary vertebrae reduced the space for the normal

592 development of the other centrums, which ended compressing the vertebrae (also referred to

593 as platyspondyly). In this sense, Faustino and Power (2001) showed a clear relationship

594 between the incidence of lordotic gilthead sea bream and the frequency of specimens with

595 twenty-three vertebrae. The appearance of vertebral fusions might be attributed to a defect of

596 notochord segmentation and disruption of vertebral centrum differentiation, which might be a

597 result of a VA-induced accelerated skeletogenesis. In addition, the higher incidence of vertebral

598 deformities in the cephalic and prehaemal vertebrae (15-18\%) in fish exposed to the highest

599 VA level $(R 4,500)$ in contrast to the other dietary regimes $(<5 \%)$, showed that high doses of VA 
accelerated the normal differentiation pattern of vertebral centrums of these regions that

601 appear chronologically earlier (Faustino and Power, 1998).

602 The caudal fin complex was the most affected region of the gilthead sea bream skeleton

603 affected by dietary treatments as seen by the high incidence of skeletal deformities in fish fed

604 different doses of dietary VA. Deformities affected all skeletal elements composing the caudal

605 fin, although the most affected were, in order of importance, the epurals, hypurals, parahypural,

606 neural arch and uroneurals. The skeletal elements that compose the caudal fin (urostyle and fin

607 elements) are formed either by endochondral or by intramembranous ossification (Gavaia et

608 al., 2002). The first group included the parahypural, hypurals, epurals, uroneurals and the

609 specialized neural arch; and the second group included the vertebra 23 , the urostyle and the

610 caudal fin rays. The present results indicate that independently of the ossification process type

611 that takes place in the different skeletal elements that compose the caudal fin, it seems that the

612 effect of dietary VA is the same, and might be more related to the intense ossification process

613 induced by the VA that disrupted the normal and harmonious development of the above-

614 mentioned skeletal elements. Differences in sensitivity to dietary VA amongst caudal fin

615 skeletal elements might be due to their differential ontogenetic development, and to differences

616 in the exposure time to VA. Thus, the skeletal structures more sensitive to dietary VA were

617 those that differentiated earlier, such as epurals, hypurals and parahypurals, whose cartilages

618 appeared between $4.4-5.1 \mathrm{~mm}$ Ls and were not completely ossified until $14.7-16.0 \mathrm{~mm}$ Ls

619 (Faustino and Power 1998). In contrast, the uroneurals, which appeared at larger sizes (10.4 -

$62016.0 \mathrm{~mm}$ Ls, Faustino and Power 1998) when all the elements of the caudal complex were

621 already ossified, were less affected by dietary treatments $(<5 \%)$ due to its late ossification

622 process (Koumoundouros et al. 1997a; Faustino and Power 1998).

623 Although dietary VA affected the incidence of skeletal deformities in the caudal fin

624 complex, these abnormalities were not lethal but seriously affected the external appearance

625 and quality of larvae and juveniles, confirming the data reported by Koumoundouros et al.

626 (1997a). These results are in agreement with those already published from wild-caught and 
627 hatchery reared gilthead sea bream (Koumoundouros et al., 1997a; Boglione et al., 2001),

628 although differences in the typology and frequencies of different skeletal deformities exist

629 amongst studies. The incidence of skeletal deformities in the caudal complex was affected by

630 the levels of dietary VA, the higher the VA dose, the higher the incidence of deformed skeletal

631 elements. Similar results have been obtained in summer flounder (Martínez et al., 2007), and

632 Japanese flounder exposed to different levels and forms of this nutrient by means of balneation

633 (Haga et al., 2002a) and dose-response dietary trials (Dedi et al., 1998; Haga et al., 2002b). In

634 contrast to Haga et al. (2002a, b), we did not find any case of partial or complete absence of

635 the caudal fin when larvae were exposed to high levels of dietary VA. Such differences

636 between different studies might be due to different levels of retinoic acid to which larvae were

637 exposed, independently to the experimental approach used (balneation or dose-response trial).

638 According to the former authors, retinoic acid would inhibit cartilage differentiation before the

639 commencement of chondrocytes formation, causing the loss of the hypural, which would result

640 in the loss of the caudal fin.

641 In conclusion, different dietary doses of VA affected gilthead sea bream larval growth, 642 survival, performance (maturation of the digestive system) and quality (incidence of skeletal 643 deformities). Higher levels of dietary VA than those included in the commercial emulsion for 644 rotifer enrichment led to different levels and typologies of skeletal deformities, indicating that 645 gilthead sea bream larvae were very sensitive to dietary levels of VA (an increase of only 1.5 646 times of total VA in enriched rotifers, significantly increased the incidence of skeletal 647 deformities). Dietary VA affected the normal process of bone formation and skeletogenesis, the 648 skeletal structures mostly affected by high amounts of dietary VA were those from the cranial 649 skeleton (splanchnocranium), vertebral centrums and caudal fin complex. An excess of dietary 650 VA also accelerated the intramembranous ossification process of vertebral centrums leading to 651 a supranumerary vertebra, and a high incidence of fused and compressed vertebrae. Further 652 studies are needed to evaluate the effect of VA on larval quality and the molecular mechanisms 653 involved in skeletogenesis. Moreover, the sensibility of the developing skeletal structures to 
dietary VA levels should incline us to test lower doses of VA in live preys enrichments during 655 early larval stages and higher doses afterwards.

656

657

\section{Acknowledgments}

659 Authors would like to express their gratitude to J. Canoura, M. Monllaó and N. Gras for their 660 excellent technical assistance with live prey rearing. This work was funded by the Ministry of 661 Education and Culture (MEC) of the Spanish Government (project AGL2005-02478). The 662 collaboration with Y.K. (HMCR, Greece) was established thanks to the HG2004-0018 grant 663 (MEC, Spain). I.F was supported by a predoctoral MEC fellowship and E.G. by the Programa 664 Ramón y Cajal (MEC, Spain).

665

666

667 References

668

Andrades, J.A., Becerra, J., Fernandez-Llebrez, P., 1996. Skeletal deformities in larval, juvenile and adult stages of cultured gilthead sea bream (Sparus aurata L.). Aquaculture 141, 1 11.

Barahona-Fernandes, M.H., 1982. Body deformation in hatchery reared European sea bass (Dicentrarchus labrax CL.). Types, prevalence and effect on fish survival. J. Fish Biol. 21, 239-249.

Başaran, F., Muhtaroğlu, G., Ilgaz, S., Boyacıoğlu, H., 2004. The Effect of Tank Volumes on Survival of Gilthead Seabream (Sparus aurata L., 1758) from Hatching to the First Grading in Intensive Culture Systems. E. U. J. Fisher. Aquat. Sci. 21, 69-72.

679 Beraldo, P., Pinosa, M., Tibaldi, E., Canavese, B., 2003. Abnormalities of the operculum in gilthead sea bream (Sparus aurata): morphological description. Aquaculture 220, 89-99. 
680

681

682

683

684

685

686

687

688

689

690

691

692

693

694

695

696

697

698

699

700

701

702

703

704

705

706

Bessey, O.A., Lowry, O.H., Brock, M.J., 1946. Rapid coloric method for determination of alkaline phosphatase in five cubic millimeters of serum. J. Biol. Chem. 164, 321-329.

Boglione, C., Gagliardi, F., Scardi, M., Cataudella, S., 2001. Skeletal descriptors and quality assessment in larvae and post-larvae of wildcaught and hatchery-reared gilthead sea bream (Sparus aurata L. 1758). Aquaculture 192, 1-22.

Bradford, M.M., 1976. A rapid and sensitive method for the quantification of microgram quantities of protein utilizing the principle of protein-dye binding. Anal. Biochem. 72, 248254.

Cahu, C., Zambonino Infante, J.L., 1994. Early weaning of sea bass Dicentrarchus labrax larvae with a compound diet: effect on digestive enzymes. Comp. Biochem. Physiol. 109A, 213-222.

Cahu, C., Zambonino Infante, J.L., Takeuchi, T., 2003. Nutritional components affecting skeletal development in fish larvae. Aquaculture 227, 1- 4.

Carbó, R., Estévez, A., Furones, M.D., 2003. Intelligent and multifunctional recirculation system. Its application in research at CA-IRTA. Spec. Publ.-EAS 32, 171-172.

Chatain, B., 1994a. Abnormal swimbladder development and lordosis in sea bass (Dicentrarchus labrax) and sea bream (Sparus auratus). Aquaculture 119, 371- 379.

Chatain, B., 1994b. Quality assessment of marine fish larvae and juveniles. In: Kestemont, P., Muir, J., Sevila, F., Williot, P. (Eds.), Symposium on Measures for Success - Metrology and Instrumentation in Aquaculture Management, 23-25 March 1994, Bordeaux, France, Aquaculture, 181-183.

Crane, R.K., Boge, G., Rigal, A., 1979. Isolation of brush border membranes in vesicular form from the intestinal spiral valve of the small dogfish Scyliorhinus canicula. Biochim. Biophys. Acta 554, 264-267.

Dedi, J., Takeuchi, T., Seikai, T., Watanabe, T., 1995. Hypervitaminosis and safe levels of vitamin A for larval flounder Paralichthys olivaceus fed Artemia nauplii. Aquaculture 133, 135-146. 
Dedi, J., Takeuchi, T., Hosoya, K., Watanabe, T., Seikai, T., 1998. Effect of vitamin A levels in Artemia nauplii on the caudal skeleton formation of Japanese flounder Paralichthys olivaceus. Fish. Sci. 64, 344-345.

Divanach, P., Papandroulakis, N., Anastasiadis, P., Koumoundouros, G., Kentouri, M., 1997. Effect of water currents during postlarval and nursery phase on the development of skeletal deformities in sea bass (Dicentrarchus labrax L.) with functional swimbladder. Aquaculture 156, 145-155.

FAO Fishery and Aquaculture Information and Statistics Service. Aquaculture production 2005. FAO yearbook. Fishery statistics. Aquaculture production. Vol. 100/2. Rome, FAO. 2007. $202 p$.

Faustino, M., Power, D.M., 1998. Development of osteological structures in the sea bream: vertebral column and caudal fin complex. J. Fish Biol. 52, 11-22.

Faustino, M., Power, D.M., 1999. Development of the pectoral, pelvic, dorsal and anal fins in cultured sea bream. J. Fish Biol. 54, 1094-1110.

Faustino, M., Power, M.D., 2001. Osteologic development of the viscerocranial skeleton in sea bream: alternative ossification strategies in teleost fish. J. Fish Biol. 58, 537-572.

Folch, J., Lees, M., Stanley G.H.S., 1957. A simple method for the isolation and purification of total lipids from animal tissues. J. Biol. Chem. 226, 497-509.

Francescon, A., Freddi, A., Barbaro, A., Giavenni, R., 1988. Daurade Sparus aurata L. reproduite artificiellement et daurade sauvage. Experiences paralleles en diverses conditions d'elevage. Aquaculture 72, 273-285.

Fraser, M.R., Nys, R., 2005. The morphology and occurrence of jaw and operculum deformities in cultured barramundi (Lates calcarifer) larvae. Aquaculture 250, 496-503.

Galeotti, M., Beraldo, P., De Dominis, S., D’Angelo, L., Ballestrazzi, R., Musetti, R., Pizzolito, S., Pinosa, M., 2000. A preliminary histological and ultrastructural study of opercular anomalies in gilthead sea bream larvae (Sparus aurata). Fish Physiol. Biochem. 22, 151157. 
734 Gavaia, P.J., Dinis, M.T., Cancela, M.L., 2002. Osteological development and abnormalities of

735 the vertebral column and caudal skeleton in larval and juvenile stages of hatchery-reared

736 Senegal sole (Solea senegalensis). Aquaculture 211, 305-323.

737 Gimenez, G., Kotzamanis, Y., Hontoria, F., Estévez, A., Gisbert, E., 2007. Modelling retinoid

738 content in live prey: A tool for evaluating the nutritional requirements and development

739 studies in fish larvae. Aquaculture 267, 76-82.

740 Haga, Y., Suzuki, T., Takeuchi, T., 2002a. Retinoic acid isomers produce malformations in

741 postembryonic development of the Japanese flounder, Paralichthys olivaceus. Zool. Sci. 19,

$742 \quad 1105-1112$.

743 Haga, Y., Takeuchi, T., Seikai, T., 2002b. Influence of all-trans retinoic acid on pigmentation

744 and skeletal formation in larval Japanese flounder. Fisheries Sci. 68, 560-570.

745 Haga, Y., Suzuki, T., Kagechika, H., Takeuchi, T., 2003. A retinoic acid receptor-selective

746 agonist causes jaw deformity in the Japanese flounder, Paralichthys olivaceus. Aquaculture

$747 \quad 221,381-392$.

748 Hernandez-H, L.H., Teshima, S., Koshio, S., Ishikawa, M., Gallardo-Cigarroa, F.J., Alam, M.S.,

749 Uyan, O., 2006. Effects of vitamin A palmitate, beta-carotene and retinoic acid on the growth

750 and incidence of deformities in larvae of red sea bream Chrysophrys major. Cienc. Mar. 32,

$751 \quad 195-204$.

752 Holm, H., Hanssen, L.E., Krogdahl, A., Florholmen, J., 1988. High and low inhibitor soybean

753 meals affect human duodenal proteinase activity differently: in vivo comparison with bovine

754 serum albumin. J. Nutr. 118, 515-520.

755 Kacem, A., Meunier, F.J., Aubin, J., Haffray, P., 2004. Caractérisation histo-morphologique des

756 malformations du squelette vertébral chez la truite arc-en-ciel (Oncorhynchus mykiss) après

757 différents traitements de triploidisation. Cybium 28, 15-23.

758 Klymkowsky, M.W., Hanken, J. 1991. Whole-mount staining of xenopus and other vertebrates.

759 Method. Cell Biol. 36, 419-425. 
760 Koumoundouros, G., Gagliardi, F., Divanach, P., Boglione, C., Cataudella, S., Kentouri, M.,

761 1997a. Normal and abnormal osteological development of caudal fin in Sparus aurata L. fry.

762 Aquaculture 149, 215-226.

763 Koumoundouros, G., Oran, G., Divanach, P., Stefanakis, S., Kentouri, M., 1997b. The

764 opercular complex deformity in intensive gilthead sea bream (Sparus aurata L.) larviculture.

$765 \quad$ Moment of apparition and description. Aquaculture 156, 165- 177.

766 Koumoundouros, G., Maingot, E., Divanach, P., Kentouri, M., 2002. Kyphosis in reared sea

767 bass (Dicentrarchus labrax L.): ontogeny and effects on mortality. Aquaculture 209, 49-58.

768 Lall, S.P., Lewis-McCrea, L., 2007. Role of nutrients in skeletal metabolism and pathology in

769 fish, an overview. Aquaculture 267, 3-19.

770 Lewis, L.M., Lall S.P., Eckhard Witten, P., 2004. Morphological descriptions of the early stages

771 of spine and vertebral development in hatchery-reared larval and juvenile Atlantic halibut

772 (Hippoglossus hippoglossus). Aquaculture 241, 47-59.

773 Loy, A., Boglione, C., Cataudella, S., 1998. Geometric morphometrics and morpho-anatomy: a

774 combined tool in the study of sea bream (Sparus. Aurata) shape. J. Appl. Ichthyol. 14, 104$775 \quad 110$

776 Maroux, S., Louvard, D., Baratti, J., 1973. The aminopeptidase from hog-intestinal brush

$777 \quad$ border. Biochim. Biophys. Acta 321, 282-295.

778 Martinez, G.M., Baron, MP., Bolker, J.A., 2007. Skeletal and pigmentation defects following

779 retinoic acid exposure in larval summer flounder, Paralichthys dentatus. J. World Aquac.

$780 \quad$ Soc. $38,353-366$.

781 Matsusato, T., 1986. Study on skeletal anomaly of fishes. Bull. Natl. Res. I. Aquac. 10, 57-179

782 (in Japanese with English abstract).

783 Mazurais, D., Darias, M.J., Gouillou-Coustans, M.F., Le Gall, M.M., Huelvan, C., Desbruyères,

784 E., Quazuguel, P., Cahu, C., Zambonino-Infante, J.L., 2008. Dietary vitamin mix levels

785 influence the ossification process in European sea bass (Dicentrarchus labrax) larvae. Am.

786 J. Physiol. Regul. Integr. Comp. Physiol. 294, 520-527. 
Métais, P., Bieth, J., 1968. Détermination de l'a-amylase par une microtechnique. Ann. Biol. Clin. 26, 133-142.

Ornsrud, R., Graff, L.E., Hoie, S., Totland, G.K., Hemre, G.I., 2002. Hypervitaminosis A in firstfeeding fry of the Atlantic salmon (Salmo salar L.). Aquacult. Nutr. 8, 7-13

Reifen, R., Zaiger, G., Uni, Z., 1998. Effect of vitamin A on small intestinal brush border enzymes in rat. Int. J. Vit. Nutr. Res. 68, 281-286.

793 Ross, S.A., Caffery, P.J., Draguer, U.C., De Luca, L.M., 2000. Retinoids in embryonal

794 development. Physiol. Rev. 80, 1021-1054.

795 Sfakianakis, D.G., Georgakopoulou, E., Papadakis, I.E., Divanach, P., Kentouri, M.,

796 Koumoundouros, G., 2006. Environmental determinants of haemal lordosis in European sea bass, Dicentrarchus labrax (Linnaeus, 1758). Aquaculture 254, 54-64.

798 Subasinghe, R., 1997. Fish health in quarantine. Review of the state of the world aquaculture.

799 FAO Fisheries Circular N ${ }^{\circ}$ 886. Food and Agriculture Organisation of the United Nations, $800 \quad$ Rome, 45-49.

801 Takashima, F., 1978. Vertebral malformation in hatchery-reared red sea-bream, Chrysophryus 802 major. Bull. Jpn. Soc. Sci. Fish. 44, 435-443.

803 Takeuchi, T., Dedi, J., Ebisawa, C., Watanabe, T., Seikai, T., Hosoya, K., Nakazoe, J.I., 1995.

804 The effect of Beta-carotene and Vitamin-A enriched Artemia nauplii on the malformation and 805 color abnormality of larval Japanese flounder. Fish. Sci. 61, 141-148.

806 Takeuchi, T., Dedi, J., Haga, Y., Seikai, T., Watanabe, T., 1998. Effect of vitamin A compounds 807 on bone deformity in larval Japanese flounder (Paralichthys olivaceus). Aquaculture 169, $808 \quad 155-165$.

809 Takeuchi, T., Dedi, J., Haga, Y., Seikai, T., Watanabe, T., 1998. Effect of vitamin A compounds 810 on bone deformity in larval Japanese flounder Paralichthys olvaceus. Aquaculture 169, $811 \quad 155-165$. 
812 Tandler, A., Anav, F.A., Choshniak, I., 1995. The effect of salinity on growth rate, survival and

813 swimbladder inflation in gilthead seabream, Sparus aurata, larvae. Aquaculture 135, 343-

814353.

815 Tarui, F., Haga, Y., Ohta, K., Shima, Y., Takeuchi, T., 2006. Effect of Artemia nauplii enriched 816 with vitamin A palmitate on hypermelanosis on the blind side in juvenile Japanese flounder 817 Paralichthys olivaceus. Fish. Sci. 72, 256-262.

818 Uni, Z., Zaiger, G., Gal-Garber, O., Pines, M., Rozenboim, I., Reifen, R., 2000. Vitamin A 819 deficiency interferes with proliferation and maturation of cells in the chicken small intestine. $820 \quad$ Br. Poult. Sci. 41, 410- 415.

821 Verhaegen, Y., Adriaens, D., De Wolf, T., Dhert, P., Sorgeloos, P., 2007. Deformities in larval 822 gilthead sea bream (Sparus aurata): A qualitative and quantitative analysis using geometric 823 morphometrics. Aquaculture 268, 156-168.

824 Villeneuve, L., Gisbert, E., Le Delliou, H., Cahu, C.L., Zambonino-Infante, J.L., 2005a. Dietary 825 levels of all-trans retinol affect retinoid nuclear receptor expression and skeletal 826 development in European sea bass larvae. Br. J. Nutr. 93, 1-12.

827 Villeneuve, L., Gisbert, E., Zambonino-Infante, J.L., Quazuguel, P., Cahu, C.L., 2005b. Effects 828 of lipids on European sea bass morphogenesis: implication of retinoid receptors. Br. J. Nutr. $82994,877-884$.

830 Villeneuve, L., Gisbert, E., Moriceau, J., Cahu, C.L., Zambonino Infante J.L., 2006. Intake of 831 high levels of vitamin A and polyunsaturated fatty acids during different developmental 832 periods modifies the expression of morphogenesis genes in European sea bass 833 (Dicentrarchus labrax). Br. J. Nutr. 95, 677-687.

834 Zambonino-Infante, J.L., Cahu, C.L., 2001. Ontogeny of the gastrointestinal tract of marine fish 835 larvae. Comp. Biochem. Physiol. 130, 477- 487.

836 Zar, J.H., 1974. Biostatistical Analysis. Prentice Hall, Englewood Cliffs, NJ. USA. 837 838 
839

840 


\section{$841 \quad$ Figure captions}

842 Figure 1. Final size distribution of gilthead sea bream larvae fed rotifers enriched with graded

843 levels of vitamin A.

845 Figure 2. Specific enzyme activity in larvae $18 \mathrm{dph}$ fed with the different diets for trypsin (a) and

846 amylase (b) expressed in $\mathrm{U} \mathrm{mg}^{-1}$ prot DW, and in larvae at $60 \mathrm{dph}$ for trypsin in $\mathrm{mU} \mathrm{mg}^{-1}$ prot

847 DW (c) and for amylase in $\mathrm{U} \mathrm{mg}^{-1}$ prot DW (d). Different indexed letters show significant

848 differences between treatments (ANOVA, $P<0.05$ ).

849

850 Figure 3. Specific enzyme activity in $18 \mathrm{dph}$ larvae fed with the different diets measured in $\mathrm{U}$

$851 \mathrm{mg}^{-1}$ prot DW for alkaline phosphatase (a) and aminopeptidase $\mathrm{N}(\mathrm{b})$, and in larvae at $60 \mathrm{dph}$

852 (c) and (d), respectively. Different indexed letters show significant differences between

853 treatments (ANOVA, $P<0.05)$.

855 Figure 4. Degree of ossification (Stages I-VI) of larvae fed different levels of VA-enriched

856 rotifers. The description of each stage of ossification is presented in the text.

858 Figure 5. Different types of mandibular deformities. Fish with normal developed upper and

859 lower jaws (a), fish with lower jaw (dentary) deformed (b), fish with the upper jaw (premaxillar)

860 deformed (c). Abbreviations: An, angular; De, dentary; Fr, frontal; Mx, maxillar; Nas, nasal; Pm,

861 premaxillar; Ps, parasphenoid; Sc, sclerotic.

862

863 Figure 6. Cranial deformities in gilthead sea bream fed different levels of VA. Frequencies of

864 fish with mandibular (a, b) and opercular complex (c, d) skeletal deformities. Different letters

865 show significant differences between treatments (ANOVA, $P<0.05$ ).

866 
Figure 7. Frequency of gilthead sea bream larvae fed different doses of dietary VA with

868 different number of vertebrae.

869

870 Figure 8. Frequency of fishes fed different levels of VA with lordotic, kyphotic or scoliotic

871 vertebral column (a), with at least one vertebral deformity (b), fused vertebral centrums (c) and

872 compressed vertebral centrums (d). Different letters show significant differences between

873 treatments (ANOVA, $P<0.05)$.

874

875 Figure 9. Fish with severe lordosis and kyphosis on their vertebral column.

876

877 Figure 10. Incidence of vertebral deformities (vertebral compression and fusion) along the vertebral axis in larvae fed rotifers enriched with R450 (a), R900 (b), R2,250 (c) and R4,500 (d) emulsions.

880

881 Figure 11. Incidence of deformities in the caudal fin complex in gilthead sea bream fed graded levels of VA. Percentage of specimens with at least one deformity in the caudal fin (a), specialized neural arch (b), epurals (c), hypurals and parahypural (d) and uroneural (e).

884 Different indexed letters show significant differences between treatments (ANOVA, $P<0.05$ ).

886 Figure 12. Different typologies of skeletal deformities in the caudal region of gilthead sea bream fed different levels of VA. Normal caudal fin complex developed (a), caudal fin complex with vertebral centra compressed (b), caudal fin complex with fussed preural centra 2 and 3 (c),

889 caudal fin complex with fussed hypurals and straight urostyle (d) and caudal fin complex

890 severe deformed with several vertebral centrum deformities (e). Abbreviations: Ep, epural;

891 Haem, haemal spine; Hyp, hypural; Na, specialized neural arch; Neur, neural spine; Un,

892 uroneural; Phyp, parhypurapophyses; $\mathrm{PU}_{2}, \mathrm{PU}_{3}$, preural centra 2 and 3; Vert, vertebral 893 centrum. 
894

895 
Table 1. Total lipid and retinoid content (retinyl palmitate, retinol and total VA) in experimental live prey enriching emulsions. Total lipid content is expressed as \% DW and retinoid content is expressed as $\mathrm{ng} \mathrm{mg}^{-1} \mathrm{DW}$. Different letters within the same column show statistical significant differences between emulsions (ANOVA, $P<0.05$ ).

\begin{tabular}{lcccc}
\hline Emulsion & Total lipids & Retinyl palmitate & Retinol & Total VA \\
\hline R450 & $86.8 \pm 11.9$ & $1690.9 \pm 295.91^{\mathrm{d}}$ & $6.6 \pm 1.05^{\mathrm{b}}$ & $1698.3 \pm 297.13^{\mathrm{d}}$ \\
$\mathbf{R 9 0 0}$ & $94.8 \pm 5.73$ & $3219.6 \pm 386.14^{\mathrm{c}}$ & $5.6 \pm 1.48^{\mathrm{b}}$ & $3226.3 \pm 383.95^{\mathrm{c}}$ \\
$\mathbf{R 2 , 2 5 0}$ & $95.5 \pm 1.92$ & $7973.2 \pm 768.84^{\mathrm{b}}$ & $6.8 \pm 0.25^{\mathrm{b}}$ & $7980.8 \pm 768.05^{\mathrm{b}}$ \\
$\mathbf{R 4 , 5 0 0}$ & $96.2 \pm 2.90$ & $16931.6 \pm 44.09^{\mathrm{a}}$ & $11.4 \pm 1.23^{\mathrm{a}}$ & $16946.7 \pm 443.18^{\mathrm{a}}$ \\
\hline
\end{tabular}


Table 2. Total lipid and retinoid content (retinyl palmitate, retinol, retinoic acid and total VA) in rotifers enriched graded levels of retinol palmitate. Total lipid content is expressed as \% DW and retinoid content is expressed as $\mathrm{ng} \mathrm{mg}^{-1} \mathrm{DW}$. Different letters within the same column show statistical significant differences between dietary groups (ANOVA, $P<0.05$ ).

\begin{tabular}{lccccc} 
Emulsion & Total lipids & Retinyl palmitate & Retinol & Retinoic acid & Total VA \\
\hline R450 & $8.3 \pm 0.78$ & $66.7 \pm 12.20^{\mathrm{c}}$ & $7.6 \pm 0.84^{\mathrm{c}}$ & $1.0 \pm 0.17$ & $75.4 \pm 38.72^{\mathrm{c}}$ \\
R900 & $7.8 \pm 0.66$ & $100.3 \pm 17.21^{\mathrm{b}, \mathrm{c}}$ & $8.2 \pm 0.60^{\mathrm{c}}$ & $0.8 \pm 0.29$ & $109.2 \pm 18.10^{\mathrm{c}}$ \\
$\mathbf{R 2 , 2 5 0}$ & $7.1 \pm 0.59$ & $139.1 \pm 0.90^{\mathrm{b}}$ & $49.8 \pm 7.72^{\mathrm{b}}$ & $1.1 \pm 0.28$ & $187.6 \pm 9.95^{\mathrm{b}}$ \\
R4,500 & $8.7 \pm 1.43$ & $681.9 \pm 65.54^{\mathrm{a}}$ & $68.1 \pm 7.72^{\mathrm{a}}$ & $0.9 \pm 0.28$ & $723.3 \pm 26.21^{\mathrm{a}}$
\end{tabular}


Table 3. Larval size in standard length (Ls) and dry weight (DW), and survival rate of gilthead seabream larvae fed different levels of vitamin A. Values are mean \pm standard deviation. Different letters within the same column show statistical significant differences.

\begin{tabular}{lccccc}
\hline & \multicolumn{2}{c}{ Ls (mm) } & \multicolumn{2}{c}{ DW (mg) } & Survival \\
& 18dph & 60dph & 18dph & 60dph & (\%) \\
\hline R450 & $5.33 \pm 0.48^{\mathrm{a}}$ & $16.90 \pm 2.82^{\mathrm{a}}$ & $0.087 \pm 0.028^{\mathrm{a}}$ & $74.61 \pm 8.84^{\mathrm{a}}$ & $9.1 \pm 1.9^{\mathrm{a}}$ \\
$\mathbf{R 9 0 0}$ & $4.94 \pm 0.06^{\mathrm{bc}}$ & $17.23 \pm 2.36^{\mathrm{a}}$ & $0.094 \pm 0.017^{\mathrm{a}}$ & $69.31 \pm 10.24^{\mathrm{ab}}$ & $8.0 \pm 0.2^{\mathrm{a}}$ \\
$\mathbf{R 2 , 2 5 0}$ & $4.66 \pm 0.75^{\mathrm{c}}$ & $16.40 \pm 2.48^{\mathrm{ab}}$ & $0.097 \pm 0.043^{\mathrm{a}}$ & $65.61 \pm 8.18^{\mathrm{b}}$ & $2.9 \pm 0.3^{\mathrm{b}}$ \\
$\mathbf{R 4 , 5 0 0}$ & $5.11 \pm 0.84^{\mathrm{ab}}$ & $15.66 \pm 2.03^{\mathrm{b}}$ & $0.115 \pm 0.027^{\mathrm{a}}$ & $56.86 \pm 11.27^{\mathrm{c}}$ & $3.3 \pm 0.5^{\mathrm{b}}$ \\
\hline
\end{tabular}



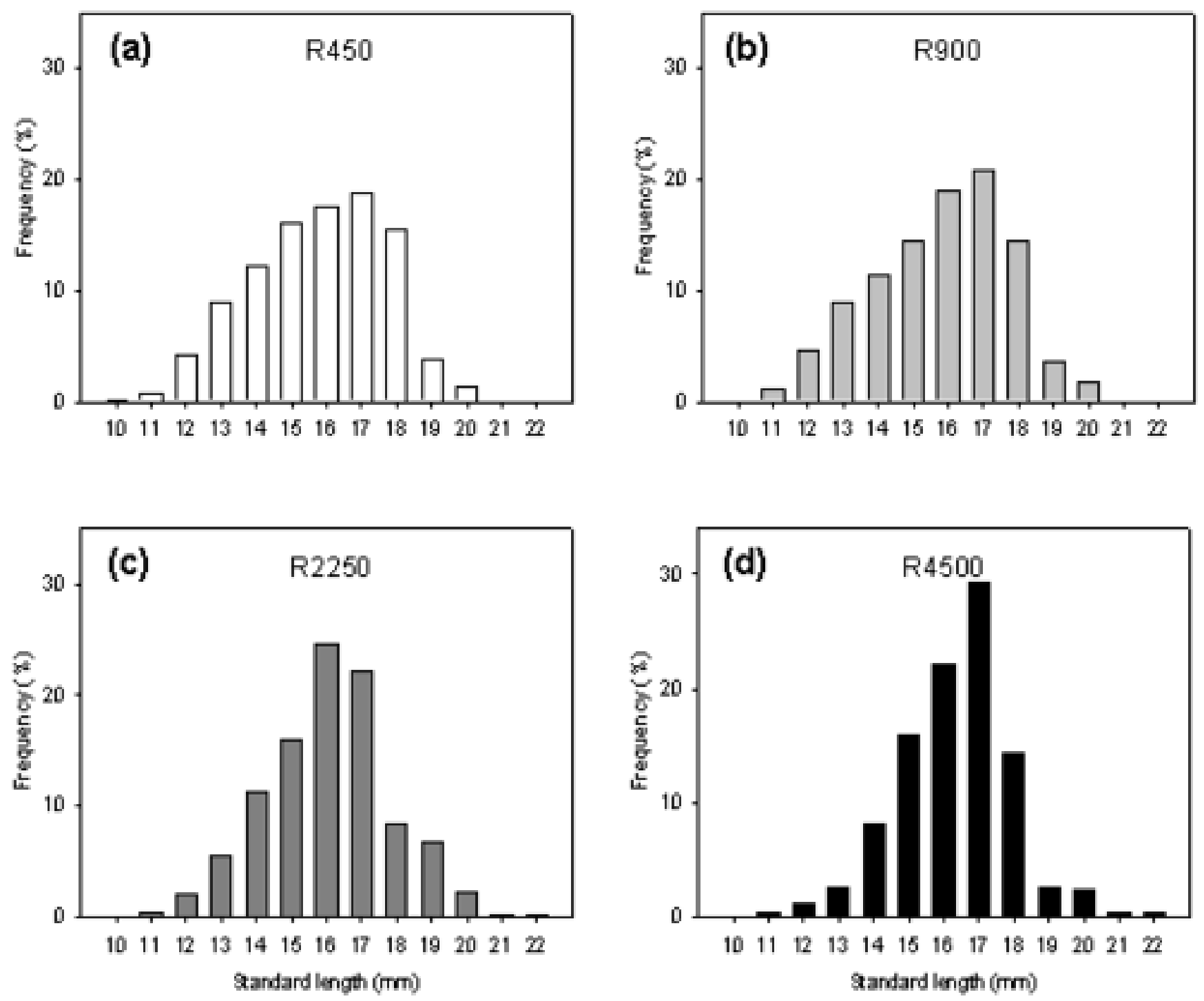

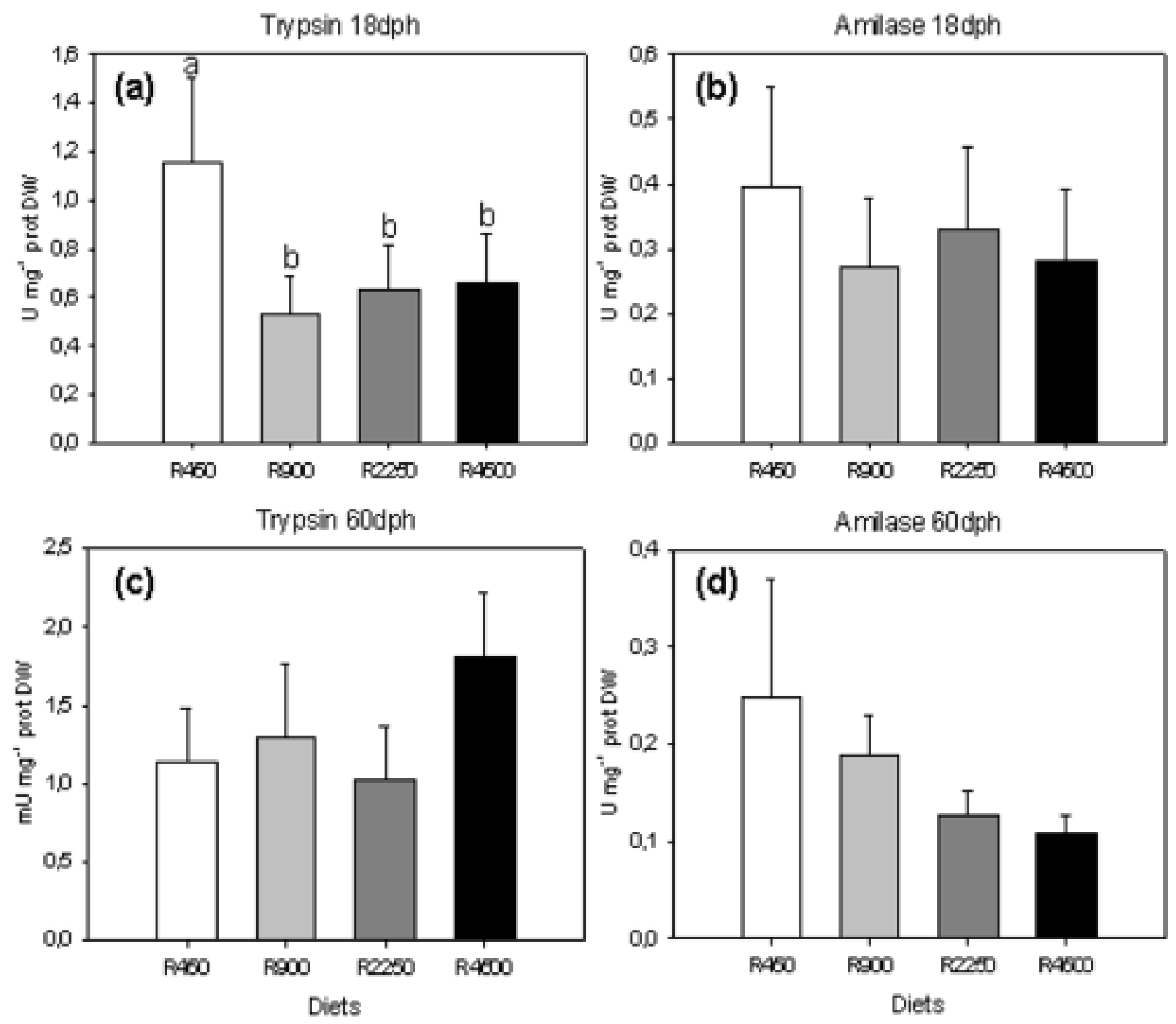

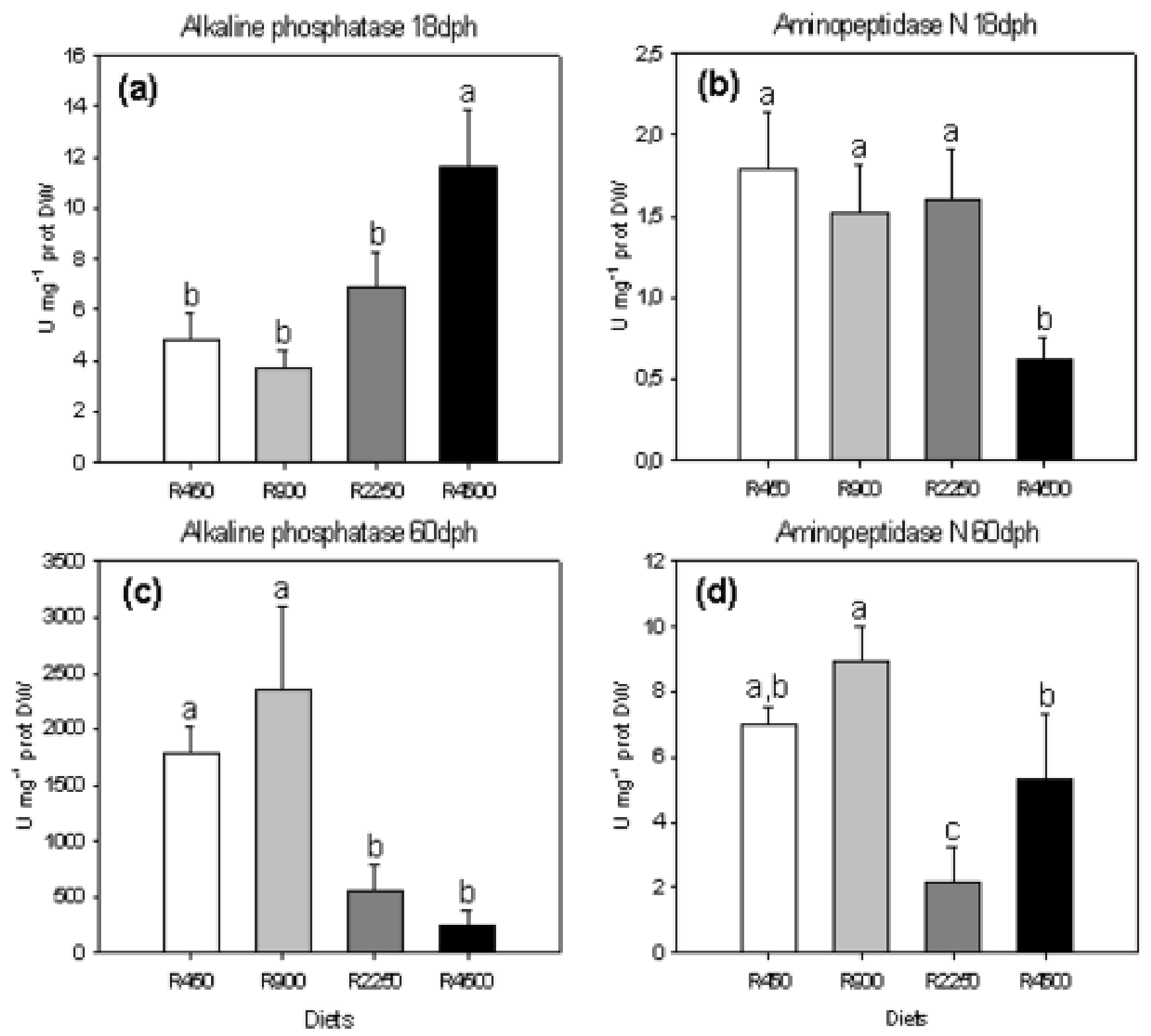
Figure 4
Click here to download high resolution image

\section{Ossification stages}

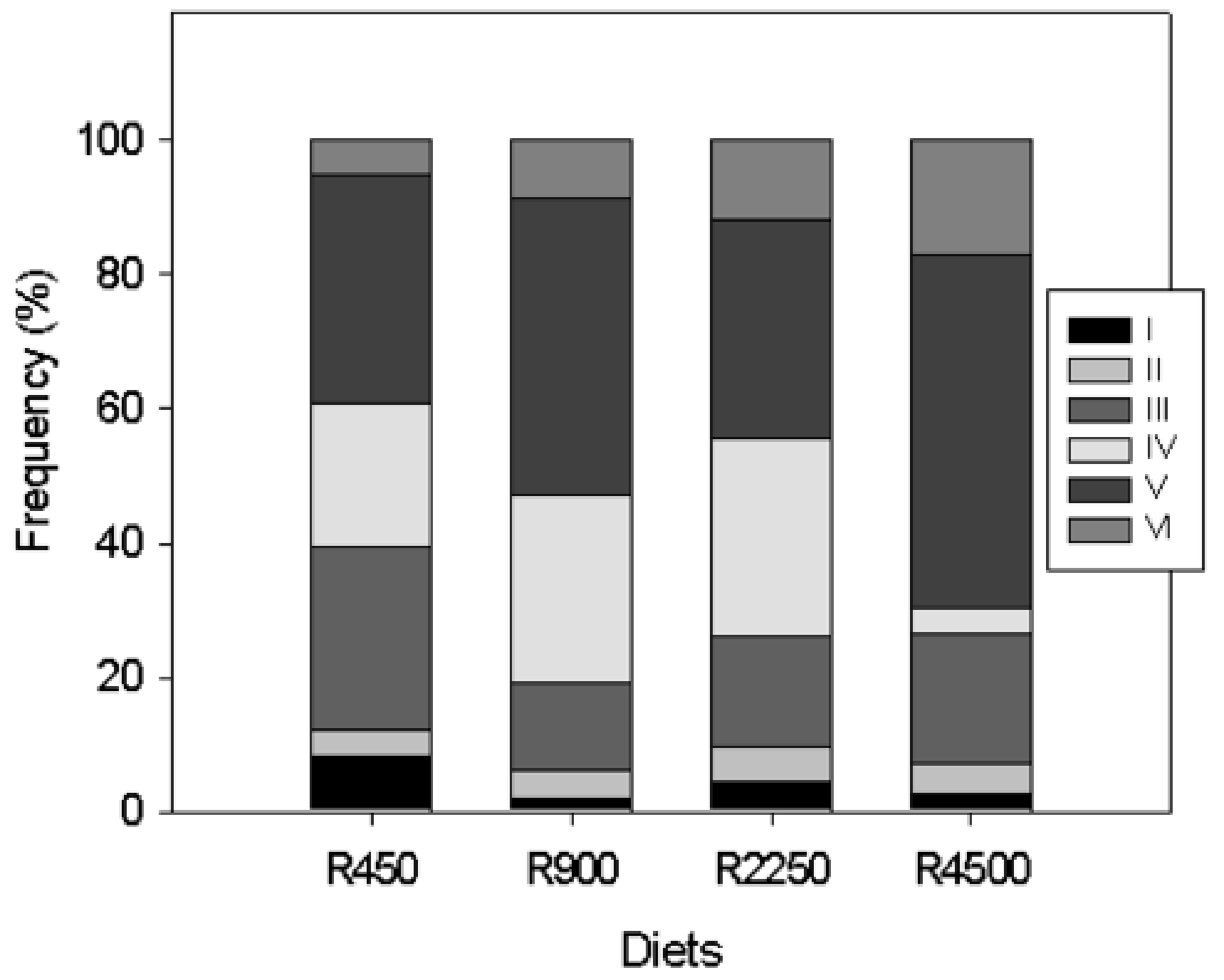


Figure 5
Click here to download high resolution image

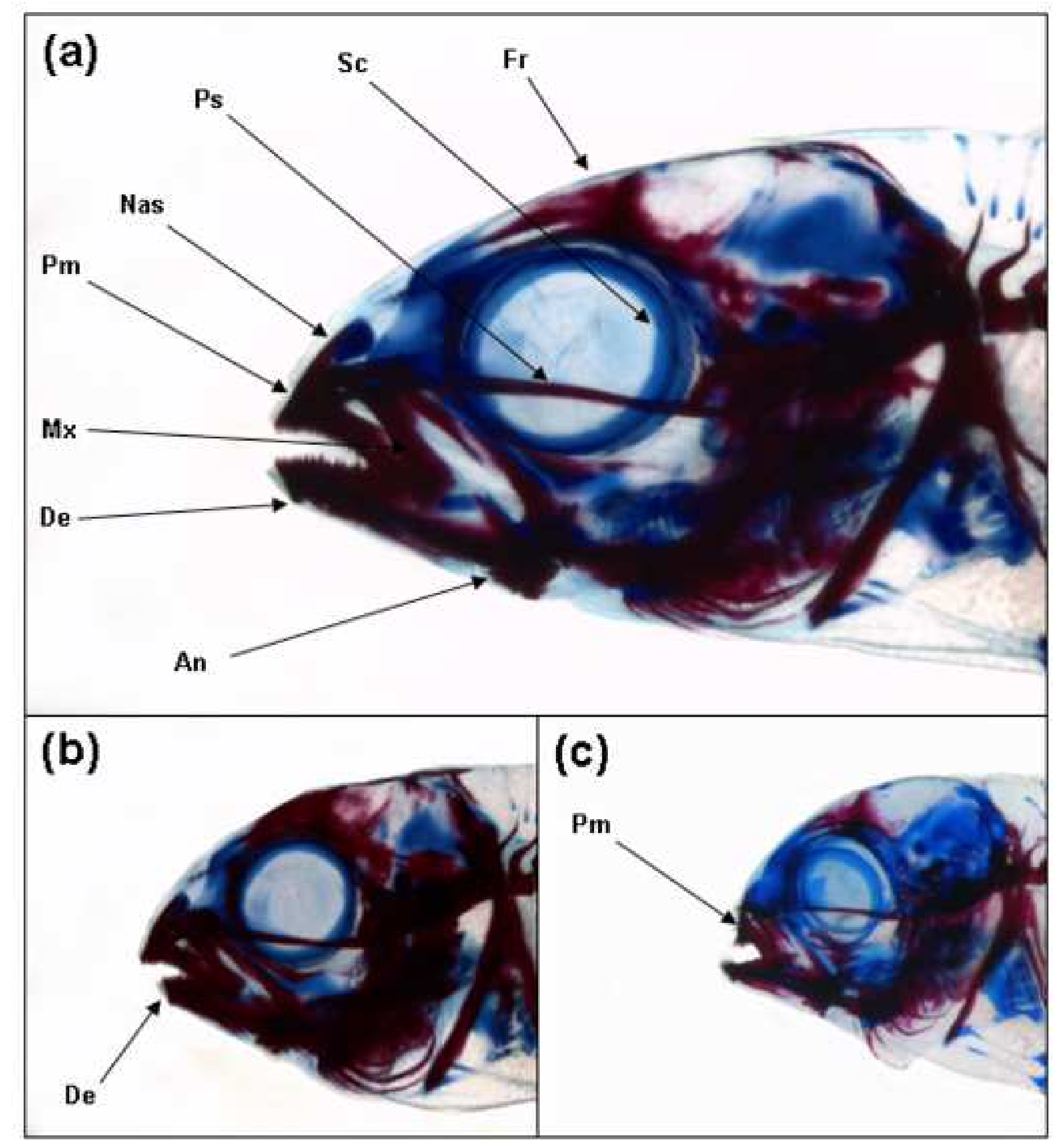



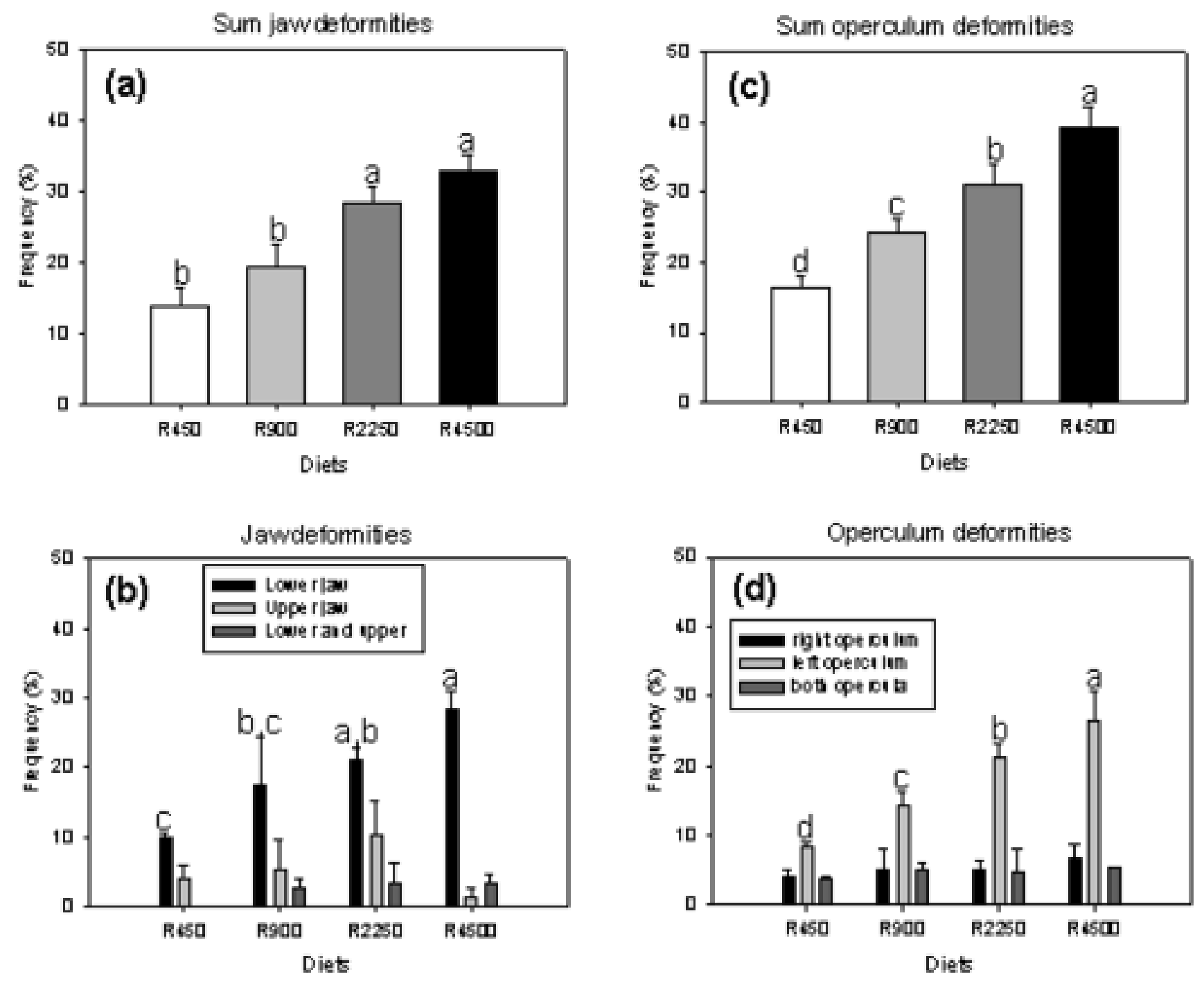
Figure 7
Click here to download high resolution image

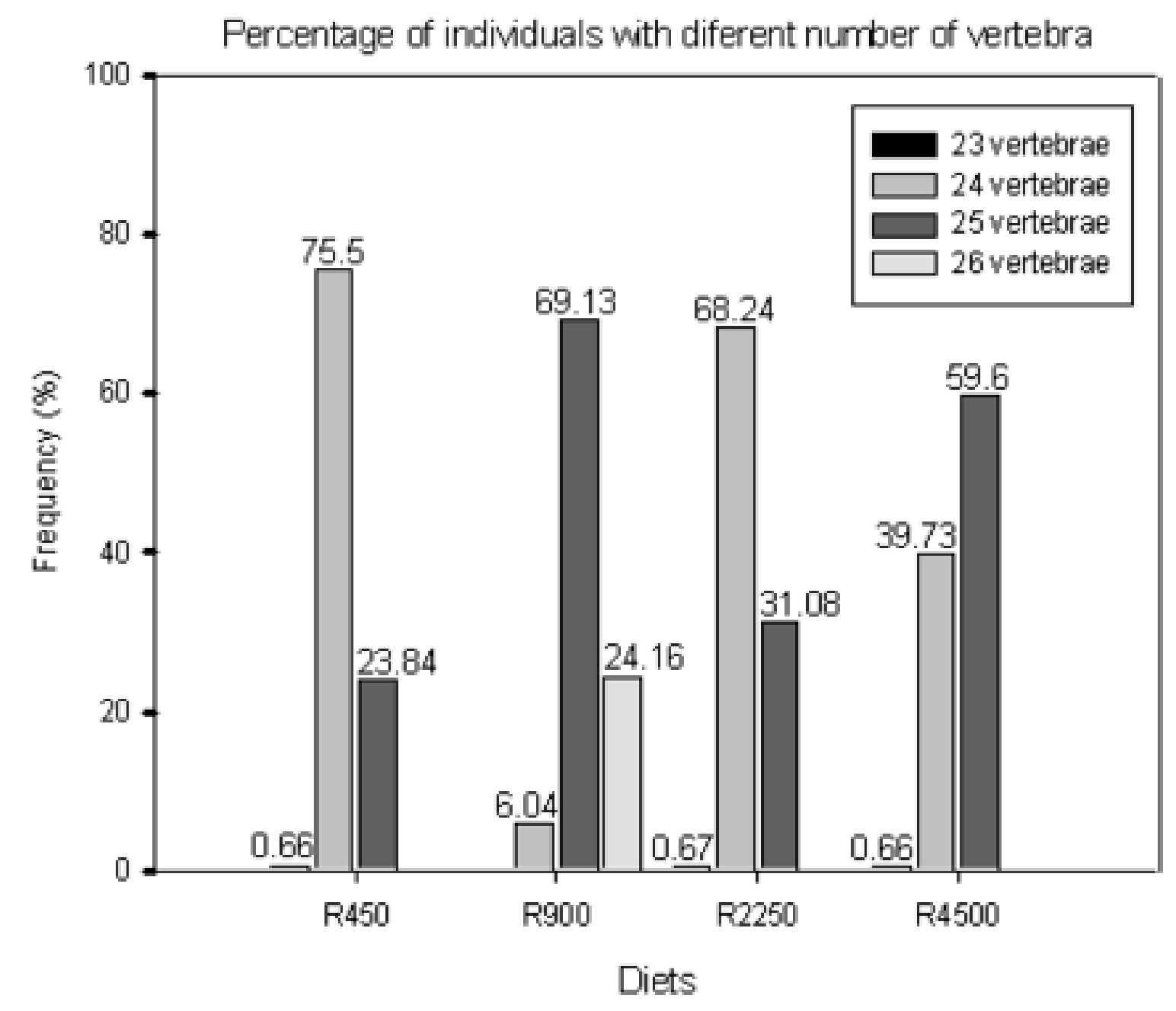



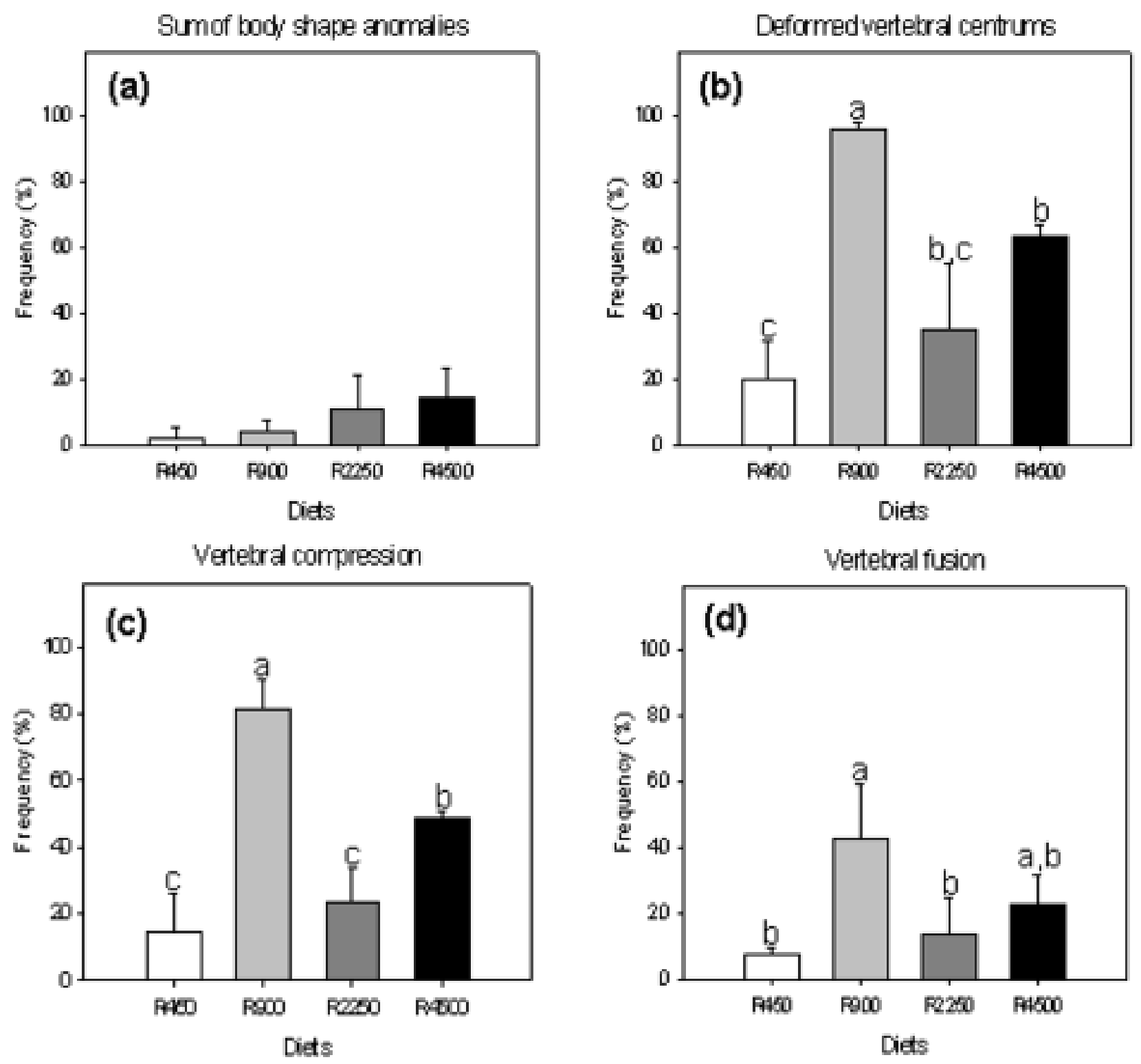
Click here to download high resolution image

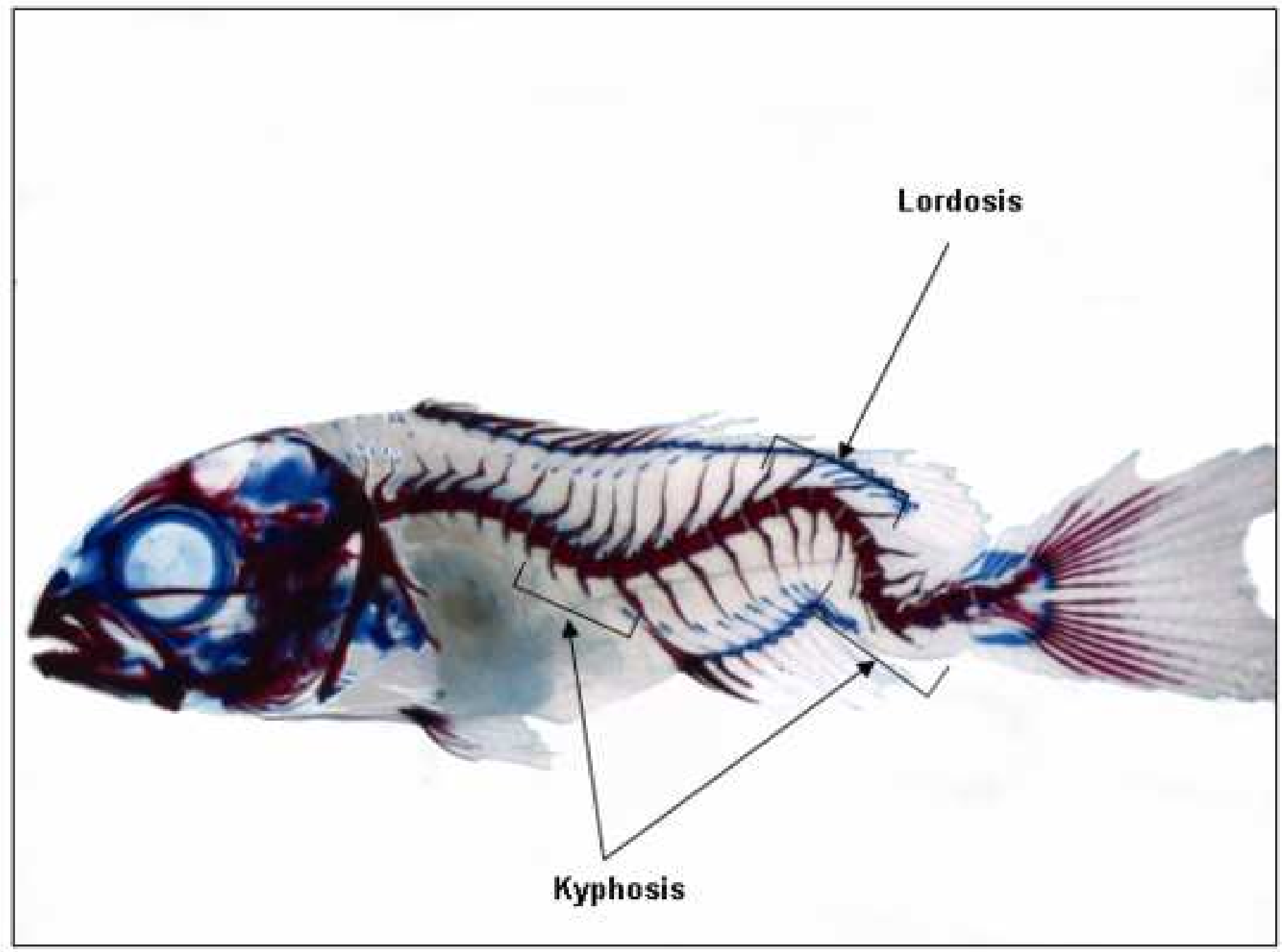


Click here to download high resolution image
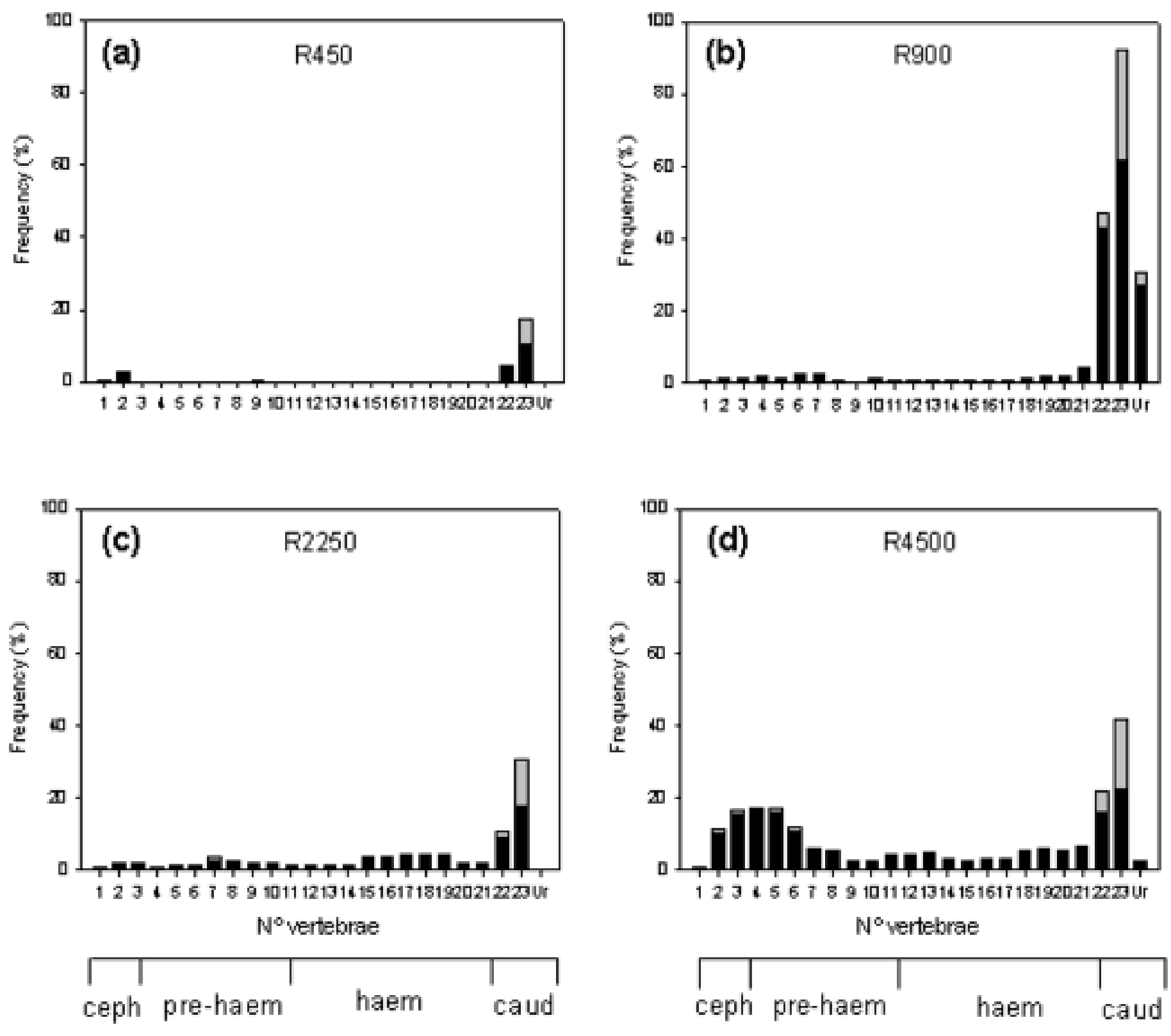
Caudal fin complex

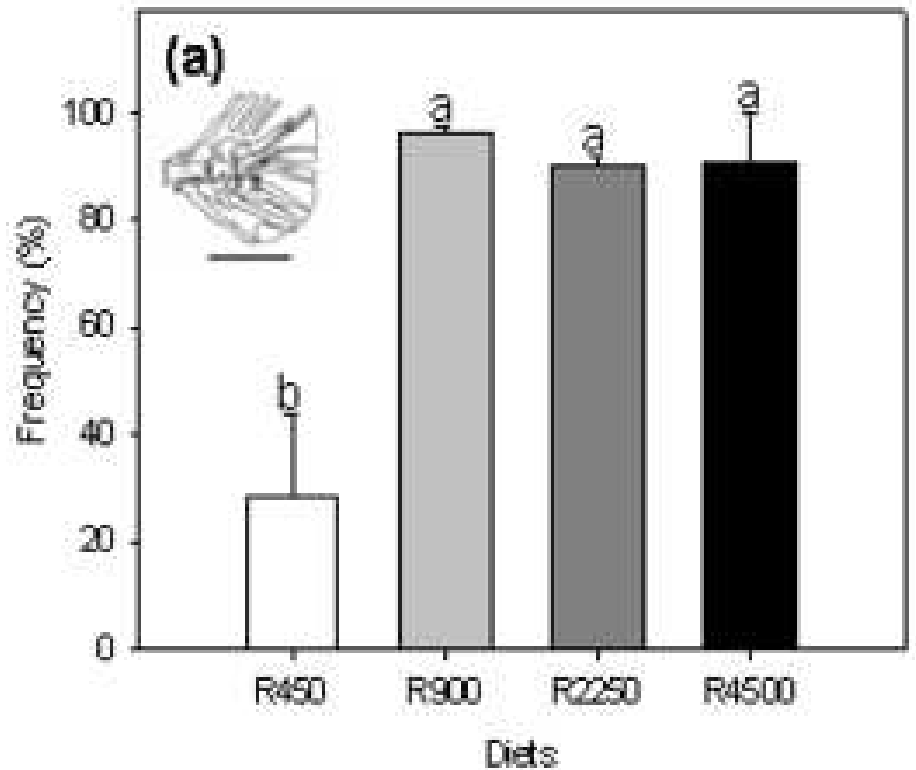

Epurals

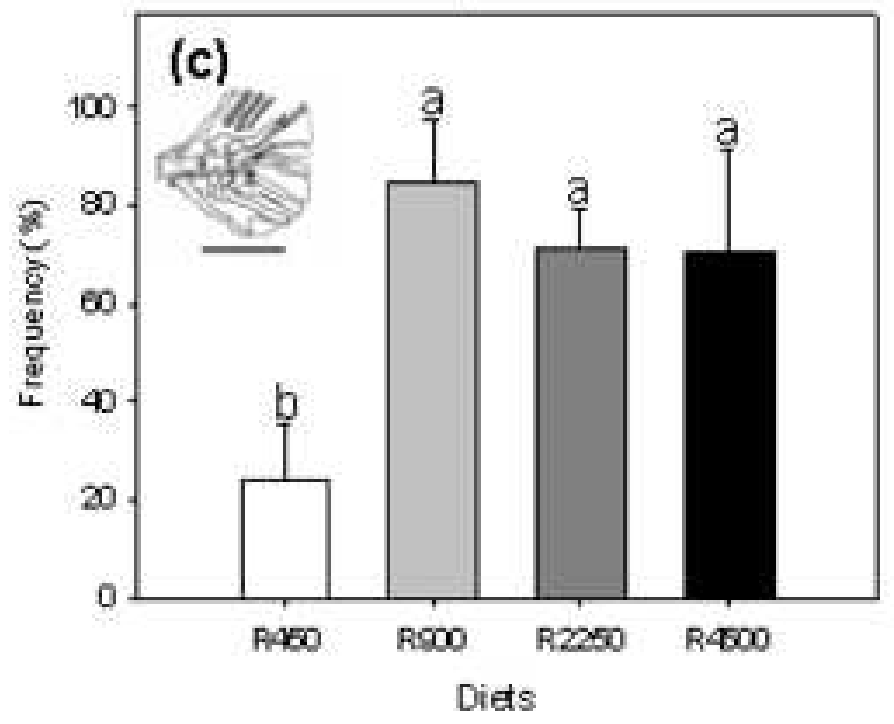

Specialized neura ach

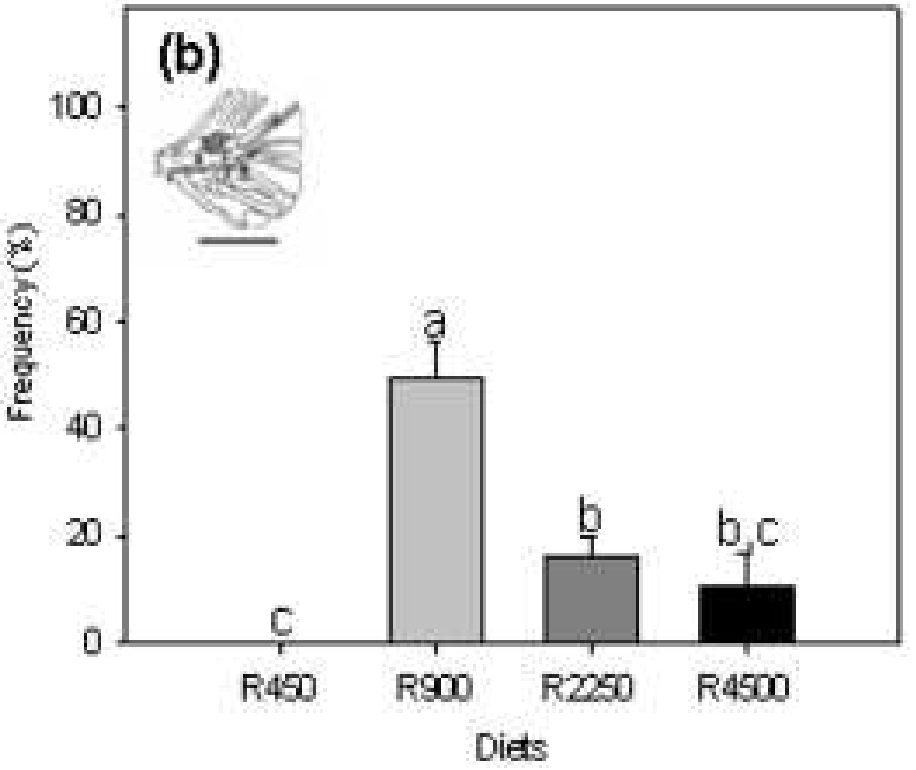

Hypurals and paratypural

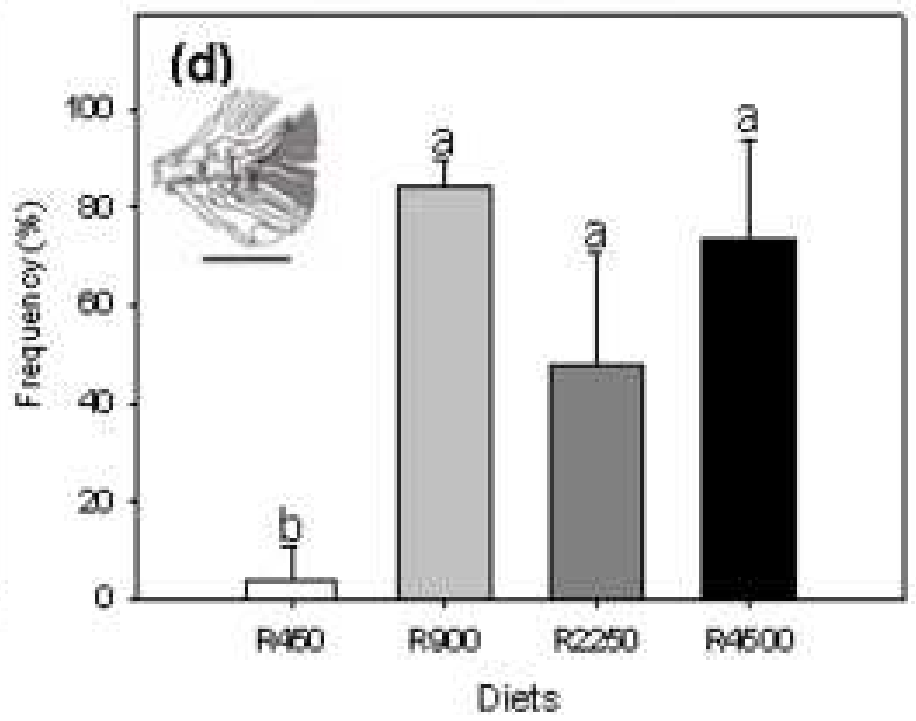

Uroneural

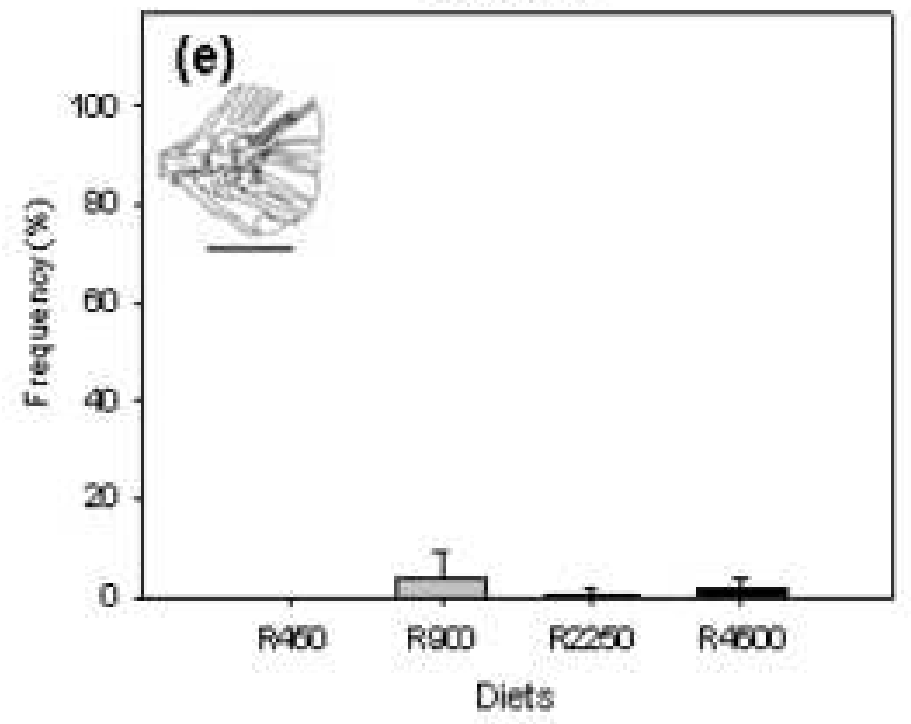


Figure 12

Click here to download high resolution image
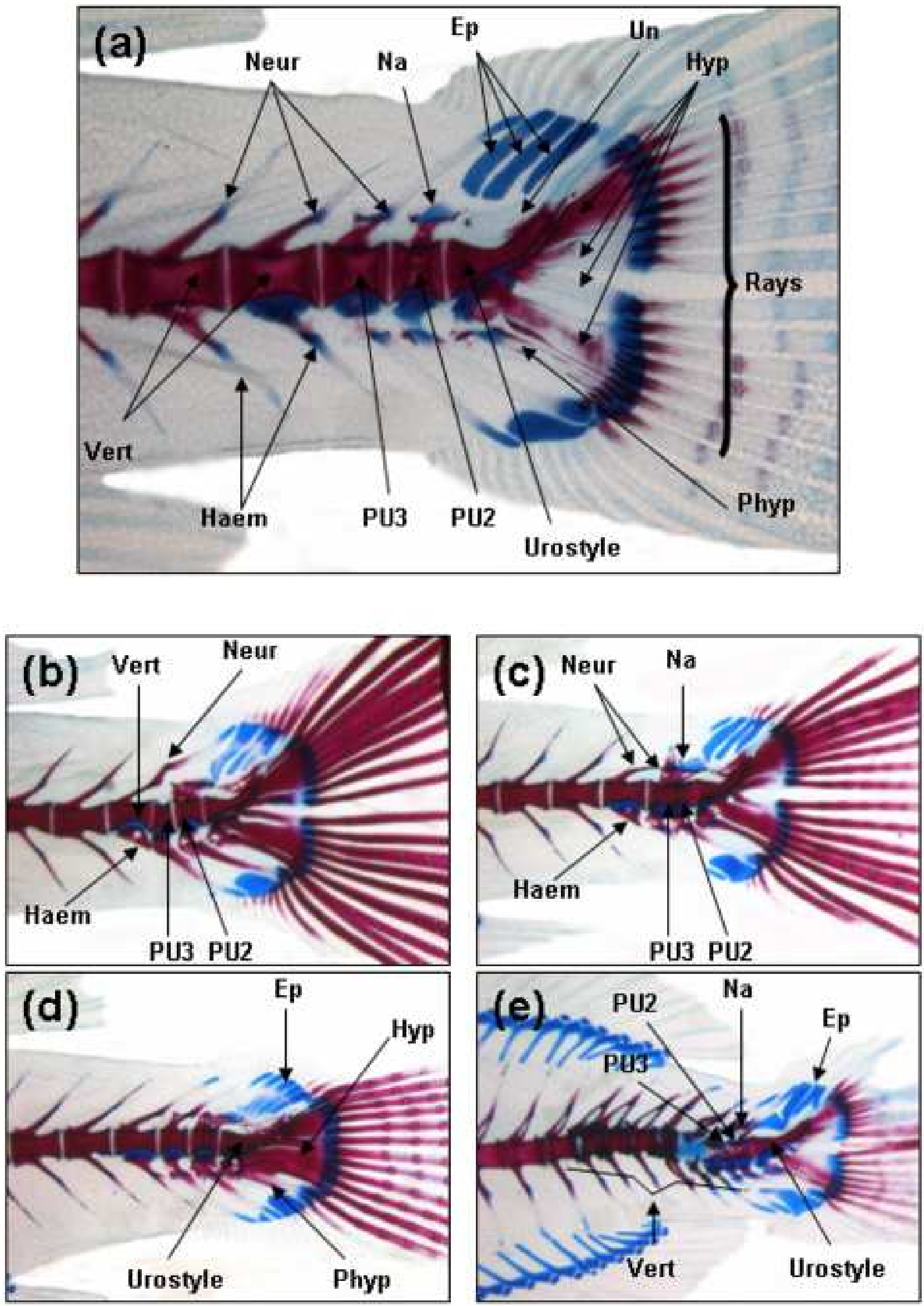